Cómo citar este artículo / How to cite this article: Tejerizo García, C., Rodríguez-González, C., Ferrer Sierra, S., Fernández Rodríguez, C., Sánchez Pardo, J. C., Fernández Pérez, J., Torres Iglesias, D., Alonso Toucido, F., Fernández-Pereiro, M., Silva Alvite, V., Mouriño Schick, A. y Pascua Ríos, C. (2021). El final del imperio romano en el noroeste peninsular: intervenciones recientes en el yacimiento de O Castelo, en Valencia Do Sil (Ourense). Lucentum, XL, 287-306. https://doi.org/10.14198/LVCENTVM.18558

\title{
EL FINAL DEL IMPERIO ROMANO EN EL NOROESTE PENINSULAR: INTERVENCIONES RECIENTES EN EL YACIMIENTO DE O CASTELO, EN VALENCIA DO SIL (OURENSE)
}

\author{
THE END OF THE ROMAN EMPIRE IN NORTHWESTERN IBERIA: RECENT RESEARCH AT THE SITE \\ OF O CASTELO, IN VALENCIA DO SIL (OURENSE)
}

CARLOS TEJERIZO GARCÍA

Universidad del País Vasco, España

carlosteje@gmail.com

https://orcid.org/0000-0001-9479-2720

CELTIA RODRÍGUEZ-GONZÁLEZ

Universidade de Santiago de Compostela, España

celtiarg@gmail.com

https://orcid.org/0000-0002-1996-0947

SANTIAGO FERRER SIERRA

Arqueólogo; Prospeccións arqueolóxicas S.L., España

santiagoferrers@yahoo.es https://orcid.org/0000-0001-9476-2847

CARLOS FERNÁNDEZ RODRÍGUEZ

Universidad de León, España

cferr@unileon.es

https://orcid.org/0000-0003-1739-1119

JOSÉ CARLOS SÁNCHEZ PARDO

Universidade de Santiago de Compostela, España

josecarlos.sanchez@usc.es https://orcid.org/0000-0003-2899-4951

JOSÉ FERNÁNDEZ PÉREZ

Geólogo independiente, España

jfernandezpepe@yahoo.es

https://orcid.org/0000-0003-2051-6138
DIEGO TORRES IGLESIAS

Universidade de Vigo, España dtorres.ig@gmail.com https://orcid.org/0000-0002-8461-7117

FRANCISCO ALONSO TOUCIDO

Universidade de Santiago de Compostela

Tempos Arqueólogos S.L., España

franalonsotoucido@hotmail.com

https://orcid.org/0000-0003-2554-5448

MARIO FERNÁNDEZ-PEREIRO

Universidade de Santiago de Compostela, España

mariofdezpereiro@gmail.com https://orcid.org/0000-0002-7704-6088

VERÓNICA SILVA ALVITE

Arqueóloga independiente, España

vero-s-a@hotmail.com

https://orcid.org/0000-0002-0565-1115

ANDREA MOURIÑO SCHICK

Universidade de Vigo, España

schickhelsingor@gmail.com

https://orcid.org/0000-0002-6861-1671

CARLA PASCUA RÍOS

Universidad Complutense de Madrid, España

carlapascuar@gmail.com

https://orcid.org/0000-0002-4697-7090

Recepción: 04/01/2021

Aceptación: 25/05/2021

Financiación: Este trabajo ha sido realizado en el marco del Proyecto «Agencia campesina y complejidad sociopolítica en el noroeste de la Península Ibérica en época medieval» (Ministerio de Economía, Industria y Competitividad, AEI/FEDER UE HUM2016-76094-C4-2-R), del Grupo de Investigación en Arqueología Medieval, Patrimonialización y Paisajes Culturales / ErdiArokoArkeologia, Ondaregintza eta KulturPaisaiakIkerketaTaldea(Gobierno Vasco, IT1193-19) y del Grupo de Estudios Rurales (Unidad Asociada UPV/EHU-CSIC). 


\section{Resumen}

En este trabajo se presentan los resultados de dos intervenciones arqueológicas realizadas en 2019 en en el yacimiento de O Castelo, en Valencia do Sil (Ourense), así como una síntesis analítica de toda la información disponible sobre el sitio. Se trata de un asentamiento fortificado que, gracias al análisis estratigráfico y las dataciones radiocarbónicas, podemos situar en los momentos finales del imperio romano en el noroeste peninsular. Así, se interpreta el enclave como un espacio de control del territorio en un momento de gran transformación política y económica. Las diferentes excavaciones llevadas a cabo en el sitio han permitido documentar dos entornos domésticos que ofrecen una importante información sobre la organización social de sus habitantes. El trabajo concluye con unas reflexiones interpretativas sobre el contexto histórico en el que se insertan este tipo de asentamientos en el norte peninsular.

Palabras clave. Asentamiento fortificado; excavación arqueológica; Gallaecia; patrón de asentamiento.

\begin{abstract}
In this paper, we present the results of two recent archaeological interventions carried out at the site of O Castelo, in Valencia do Sil (Ourense), together with an analytic synthesis of all prior available data. This is a fortified settlement which, thanks to stratigraphic analyses and radiocarbon analysis, it can be dated within the final moments of the Roman Empire in northwestern Iberia. Therefore, we interpret the site as a territorial control nucleus in a period of great political and economic changes. Different excavations have uncovered two large domestic areas which offer quite important information on the social organization of its inhabitants. This paper concludes with some interpretative thoughts on the historic context in which this type of sites are inserted in northwestern Iberia.
\end{abstract}

Key words. Fortified settlement; archaeological intervention; Gallaecia; settlement pattern.

con la Vía Nova o Vía XVIII, que discurriría desde Braga hasta Astorga, cruzando por Valdeorras hacia el Bierzo por la Serra da Enciña da Lastra (Ferrer Sierra, 2006; 2014).

El yacimiento de $\mathrm{O}$ Castelo ha sido reiteradamente excavado, pero apenas publicado, desde los años 60 hasta la actualidad (síntesis de la historiografía de este sitio pueden verse en Fernández Pereiro et al., 2017; Tejerizo García, Scaro et al., 2019), lo que le convierte en uno de los asentamientos fortificados más excavados, y a la vez menos conocidos, en el noroeste peninsular (Vigil-Escalera y Tejerizo García, 2014). Durante el año 2019 se realizaron dos intervenciones arqueológicas, una como parte de un proyecto de limpieza de los sectores excavados en los años 60 y 70 en el sitio ${ }^{1}$ y otra dentro de un proyecto de investigación ${ }^{2}$, de las cuales sintetizamos aquí los principales resultados, incluyendo un análisis de los diferentes materiales documentados. Del mismo modo, se presentará una propuesta de secuenciación de su ocupación, así como una interpretación de la funcionalidad del sitio dentro del contexto histórico y arqueológico del noroeste peninsular.

1. Dirigida por Santiago Ferrer y llevada a cabo en agosto de 2019.

2. Proyecto «Sputnik Labrego. Resiliencia e resistencia da sociedade labrega galega en 'momentos de perigo': unha análise antropolóxica e arqueolóxica na longa duración», dirigido por Carlos Tejerizo y financiado actualmente por la Universidad del País Vasco. La intervención arqueológica fue codirigida con Celtia Rodríguez y realizada en septiembre de 2019. 


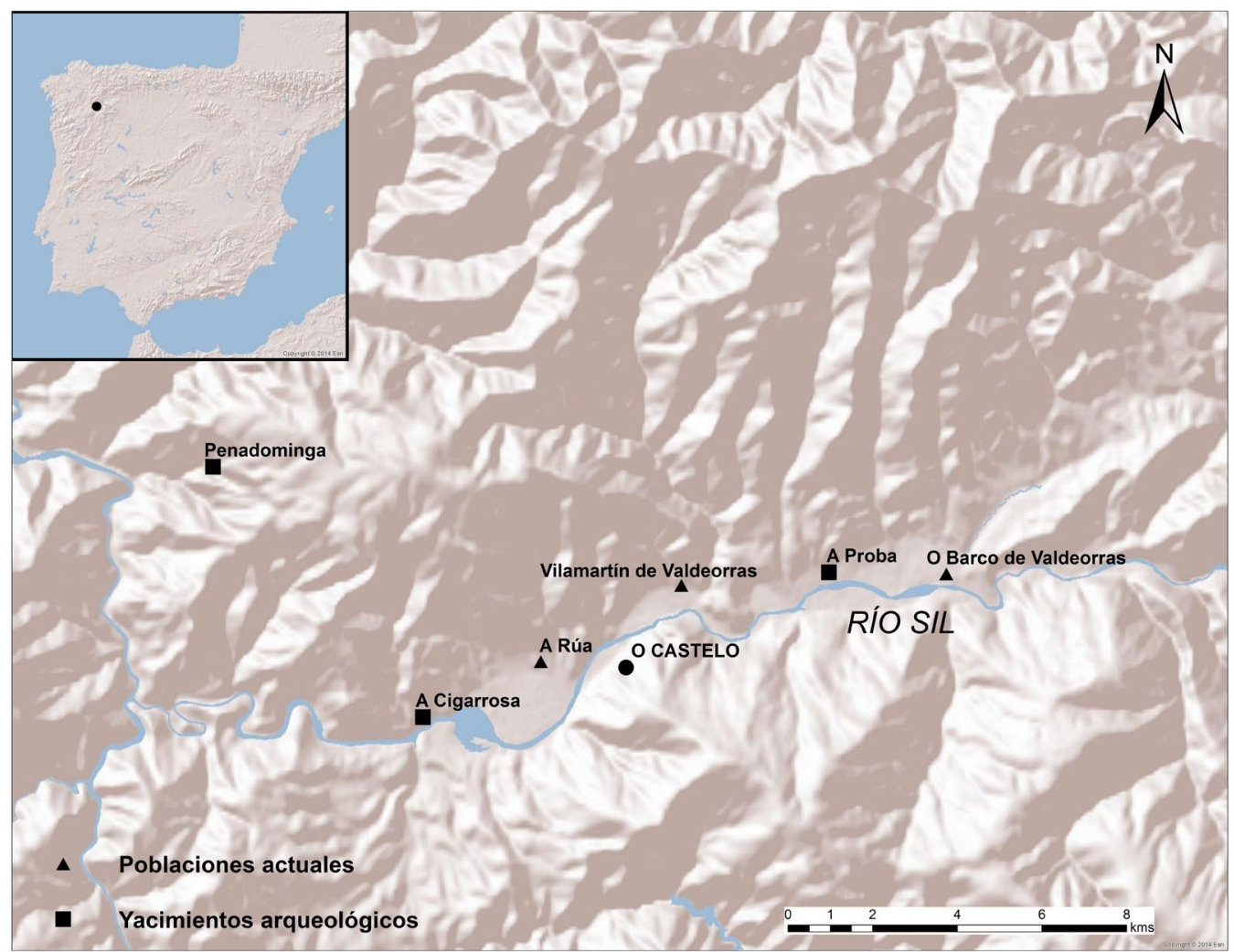

Figura 1: Localización del sitio de Valencia do Sil, yacimientos arqueológicos cercanos y poblaciones actuales de referencia

\section{ANÁLISIS PLANIMÉTRICO Y CONFIGURA- CIÓN URBANÍSTICA DE O CASTELO}

\subsection{CONFIGURACIÓN GENERAL}

Uno de los aspectos que más llama la atención del yacimiento de $\mathrm{O}$ Castelo es su estructuración interna y su disposición en el paisaje. Como describíamos al inicio, el yacimiento se asienta en la parte superior de una elevación que sobresale del conjunto montañoso, a cuyos pies se desarrolla la aldea de Valencia do Sil. En la actualidad, el sitio se encuentra rodeado en su parte oeste, sur y sureste por una construcción de piedra a modo de muro de aterrazamiento, que tradicionalmente se ha asociado con su muralla original (Fig. 3). Sin embargo, los análisis estratigráficos preliminares, a la espera de un estudio detallado de los paramentos, indican que sólo se conservarían lienzos originales en la parte sur. Concretamente, se trataría de un tramo de unos diez metros de largo con una altura aproximada de 2,5 $\mathrm{m}$ de los cuales la parte original correspondería a su parte inferior, construida a base de mampuestos de pizarra y cuarcita local que no conserva argamasa de unión. El resto de los 400 metros lineales de muro reflejarían modificaciones y añadidos posteriores, posiblemente vinculados a la instalación de los viñedos en este lugar que, en mayor o menor medida, podrían estar siguiendo el recorrido original de la muralla. La modificación más intensa de la muralla debió de producirse en la parte norte, donde se ha documentado una potencial entrada original pero que no conserva lienzos de

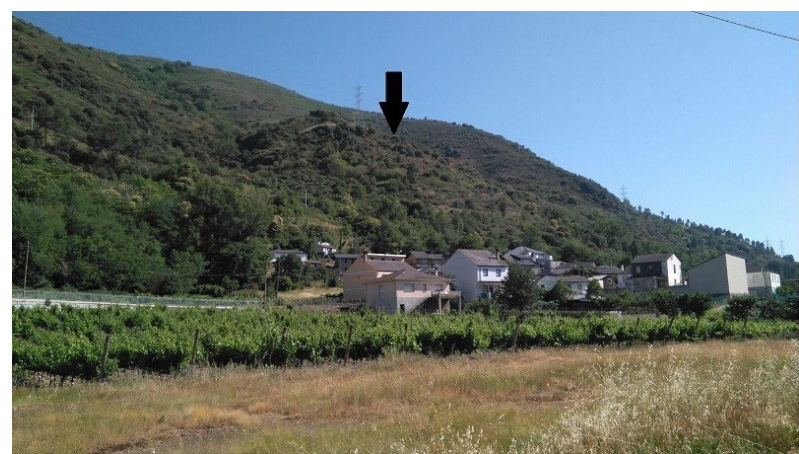

Figura 2: Contexto de Valencia do Sil. En la ladera, el pueblo actual

muralla asociados. En cualquier caso, consideramos que en la parte noreste no debió de existir amurallamiento alguno, dado que la propia configuración del sustrato geológico impediría el acceso por ese lateral. Los sistemas defensivos se complementarían con líneas de fosos paralelos de hasta $6 \mathrm{~m}$ de ancho excavados en la roca natural localizados en el extremo sureste, protegiendo la croa.

Los análisis realizados a partir de la prospección en superficie y de los datos derivados de un vuelo dron realizado en septiembre de 2019 permiten tener una idea muy detallada de la configuración del yacimiento. Este se estructuraría a partir de dos espacios principales: por un lado, la croa, de 0,3 ha de superficie y localizada en el extremo sureste; y por otro el espacio amurallado inferior, de 2 ha de extensión aproximada, lo que da un 


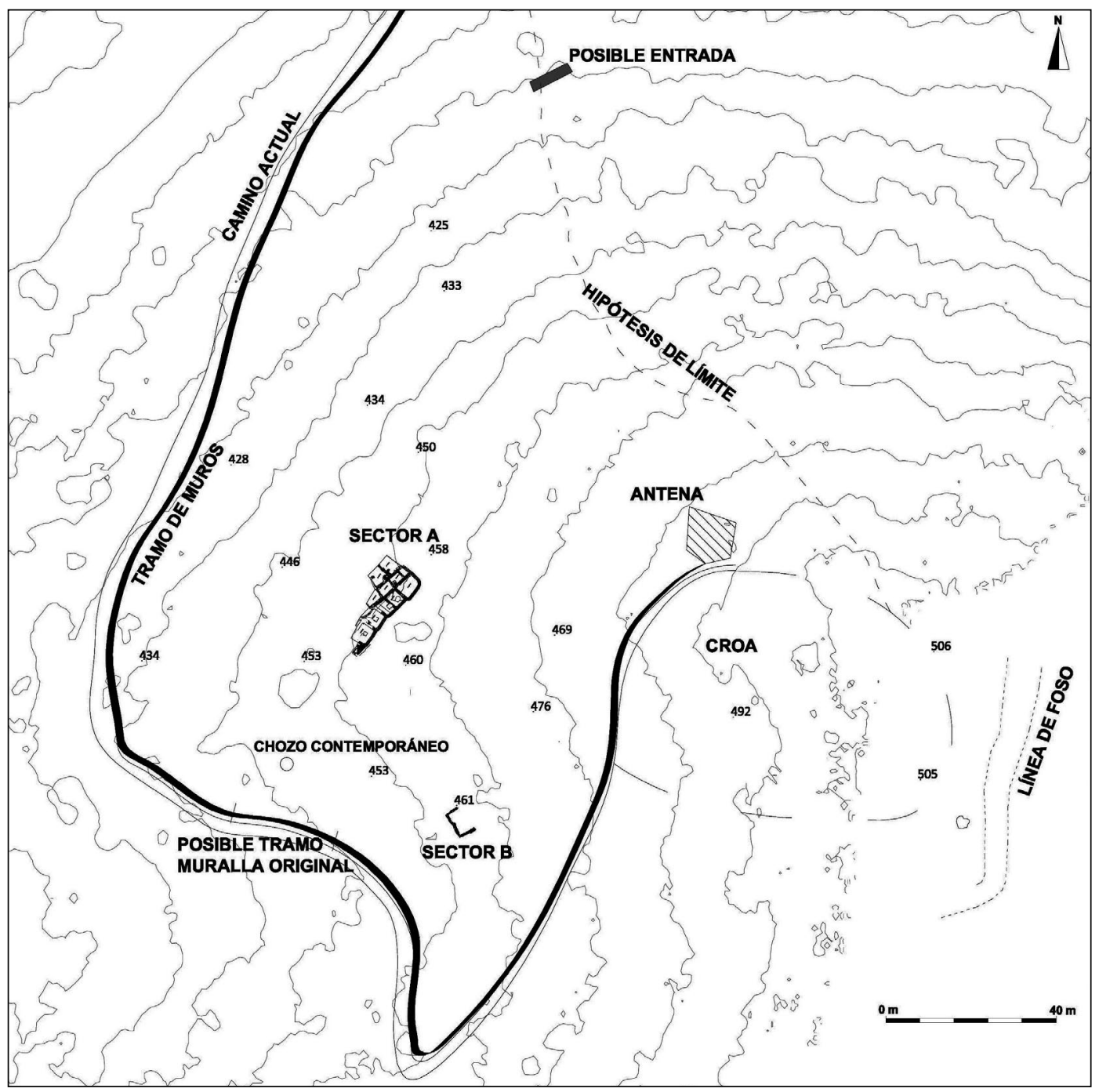

Figura 3: Planimetría general del yacimiento

total de 2,3 ha para O Castelo. Este segundo espacio se articula a través de una serie de grandes plataformas - reflejadas en la figura 3 mediante las curvas de nivel-, posiblemente entre cinco y siete, dispuestas perpendicularmente a la pendiente del terreno, donde se instalarían los edificios. En algunos casos, estas plataformas llegan a tener hasta 4 metros de altura, lo que indica el significativo esfuerzo y gasto de trabajo para la configuración del emplazamiento.

Si bien mediante los trabajos de prospección se han podido documentar estructuras y evidencias arqueológicas a lo largo de todo el yacimiento, únicamente se han confirmado y excavado en dos sectores, que denominaremos sector $\mathrm{A}$ y sector $\mathrm{B}$.

\subsection{SECTOR A}

Este sector se localiza en la zona centro-sur del yacimiento en lo que sería la segunda o la tercera plataforma del recinto interior, y fue reiteradamente excavado desde los años 60 hasta finales de los años 80 por diversos grupos de aficionados locales (Tejerizo García, Scaro et al., 2019). La limpieza realizada en 2019 tuvo como objetivo retirar la maleza acumulada en las distintas estructuras arqueológicas, así como la excavación de los últimos estratos de abandono y ocupación de una de las estancias (E09), por lo que la estratigrafía se reduce a niveles asociados a estos dos episodios.

Por el momento se conoce una extensión de $170 \mathrm{~m}^{2}$ en la que se ha exhumado un conjunto de diez espacios o «habitaciones» diferenciadas, que conformarían un «barrio» de una o quizá dos unidades domésticas, esto es, de una familia ampliada (unidad familiar más potenciales dependientes) o de dos familias compartiendo el mismo espacio. La descripción detallada de cada una de estas habitaciones se desarrolla en la tabla siguiente (Fig. 4):

En general, estas habitaciones responden a un patrón similar de planta rectangular con ángulos redondeados, que se disponen en pendiente NE-SW (Fig. $5)$. Las estructuras están formadas por muros de doble hoja de mampostería y sillarejo de esquisto y cuarcita local ligeramente escuadrada dispuesta en hileras más 


\begin{tabular}{|c|c|c|c|c|c|c|}
\hline Espacio & Zona & Nivel & Hogar & Pav. & Medidas & Características \\
\hline E01 & Norte & 1 & No & Sí & $4,60 \times 3,25 \mathrm{~m}$ & $\begin{array}{l}\text { Espacio rectangular con pavimento compuesto por material } \\
\text { latericio machacado y tierra. Excavado hasta llegar a la roca } \\
\text { madre en la zona noroeste del espacio. }\end{array}$ \\
\hline$E 02$ & Central & 1 & Sí & Sí & $5,54 \times 3,20 \mathrm{~m}$ & $\begin{array}{l}\text { Dividido en una posible fase anterior en dos partes (muro de } \\
50 \mathrm{~cm} \text { de ancho a unos } 2,63 \mathrm{~cm} \text { del muro noreste). Se trata } \\
\text { del espacio más amplio de todo el sector. El pavimento que lo } \\
\text { compone es similar a E01, se localiza en su parte noreste en } \\
\text { forma de una masa aislada. Hogar (1x } 1 \mathrm{~m} \text { ) situado en el centro } \\
\text { del espacio, encima del muro divisorio. Excavado por debajo } \\
\text { del nivel de ocupación en su zona suroeste. }\end{array}$ \\
\hline E03 & Central & 1 & Sí & Sí & $3,50 \times 3,25 \mathrm{~m}$ & $\begin{array}{l}\text { Espacio con restos de pavimento similar a las estructuras } \\
\text { anteriores, localizado en zonas aisladas. Hogar compuesto por } \\
\text { lajas de pizarra }(1 \times 1 \mathrm{~m}) \text { ubicado en la zona central del espacio. }\end{array}$ \\
\hline E04 & Sur & 1 & Sí & Sí & $3,85 \times 3,40 \mathrm{~m}$ & $\begin{array}{l}\text { Espacio con iguales características que el anterior espacio } \\
\text { (hogar y pavimento). }\end{array}$ \\
\hline E05 & Norte & 2 & No & No & $4,40 \times 1,89 \mathrm{~m}$ & $\begin{array}{l}\text { Espacio alargado al que se accede a través de dos escaleras } \\
\text { situadas en la zona sur del muro sureste y la zona norte del } \\
\text { muro noroeste. }\end{array}$ \\
\hline E06 & Norte & 3 & No & No & $2,80 \mathrm{~m}$ & $\begin{array}{l}\text { Espacio delimitado por tres muros y el final del área excavada } \\
\text { en su parte noroeste. Dentro de este espacio se ubica un } \\
\text { posible silo circular que se localiza en la zona suroeste. A este } \\
\text { espacio se accede a través del muro suroeste. }\end{array}$ \\
\hline E07 & Central & 3 & No & No & $3,54 \mathrm{~m}$ & $\begin{array}{l}\text { Espacio de delimitado igual que el anterior, al que se accede a } \\
\text { través de una escalera en el muro suroeste. }\end{array}$ \\
\hline E08 & Central & 2 & No & No & $3,46 \mathrm{~m}$ & $\begin{array}{l}\text { Espacio delimitado como los anteriores. Acceso a través del } \\
\text { muro noreste. }\end{array}$ \\
\hline$E 09$ & Central & 2 & No & Sí & $3,24 \times 2,09 \mathrm{~m}$ & $\begin{array}{l}\text { Espacio situado en la zona central del espacio. Aunque los } \\
\text { accesos no están definidos parece que pudo accederse a través } \\
\text { del vano existente del muro suroeste. }\end{array}$ \\
\hline E10 & Sur & 1 & No & Sí & $2,37 \mathrm{~m}$ & $\begin{array}{l}\text { Espacio de pequeñas dimensiones delimitado por el final } \\
\text { del área excavada. El suelo formado por rudus o piedras en } \\
\text { vertical que se dispone en casi toda el área que lo compone. }\end{array}$ \\
\hline
\end{tabular}

Figura 4: Características de los distintos espacios de Valencia do Sil en el Sector A excavados en los años 60 y 70

o menos regulares rellenadas con ripios. Aunque muy perdido, estos muros estarían unidos mediante mortero de tierra y, al menos en algunas de las estancias que lo conservan, con encalado exterior. La altura máxima de estos muros no suele superar los dos metros, siendo la zona al norte del sector, la mejor conservada en cuanto a altura, mientras que su anchura ronda los 40-60 cm. Aunque sería difícil de definir para cada habitación en particular, las evidencias tanto de tégulas como de tejas curvas y losas de pizarra indicarían el uso de techumbres tanto de un material como de otro, siempre a un agua en dirección E-W, un aspecto que podría reflejar, como hipótesis, dos momentos constructivos distintos, pero próximos en el tiempo.

$\mathrm{Al}$ igual que el resto del yacimiento, este sector se estructura a través de distintos niveles de altura excavados en la pendiente, que muestran una importante organización interna y una intencionada diferenciación funcional. En el primer nivel, el más alto, se han localizado por el momento hasta cuatro (quizás cinco) estancias. La más septentrional (E10) se caracteriza por presentar un empedrado de cantos rodados, seguramente utilizados como método de evacuación de aguas, que podrían indicar un espacio de entrada al conjunto. Las E02, E03 y E04 se caracterizan por la presencia de hogares construidos mediante lajas de esquisto, lo que podría reflejar una funcionalidad de espacio de cocina o de estancia de uso común. La E02 presenta dos singularidades: la primera es que el hogar es tipológicamente distinto al resto, dado que reutiliza piedras de granito para las esquinas; la segunda singularidad es que este hogar se sitúa por encima de un paramento que dividiría la estancia en dos, así como por encima de un relleno con materiales que, gracias a la última intervención, podrían datar del siglo IV d. n. e. (ver más abajo). Así, se puede afirmar la existencia de dos momentos constructivos que señalarían la constatación de al menos dos fases dentro de la ocupación antigua del sitio. Por su parte, la E01, la más grande del conjunto, podría asociarse a un almacén o, quizá, zona de molienda, pues en ella se localizó un molino de mano.

El segundo de los niveles está compuesto por los espacios E05, E09 y E08. Se trata de estructuras de menor tamaño situadas a una altura media entre el primer y tercer nivel, por lo que pudo servir como espacio articulador de ambos. De hecho, en la E05 se documenta una escalera situada en la parte sur que daría acceso a la E01, el posible almacén anteriormente mencionado. En este sentido, en E08 y E09 se ha documentado lo que pudo ser un pavimento de opus 

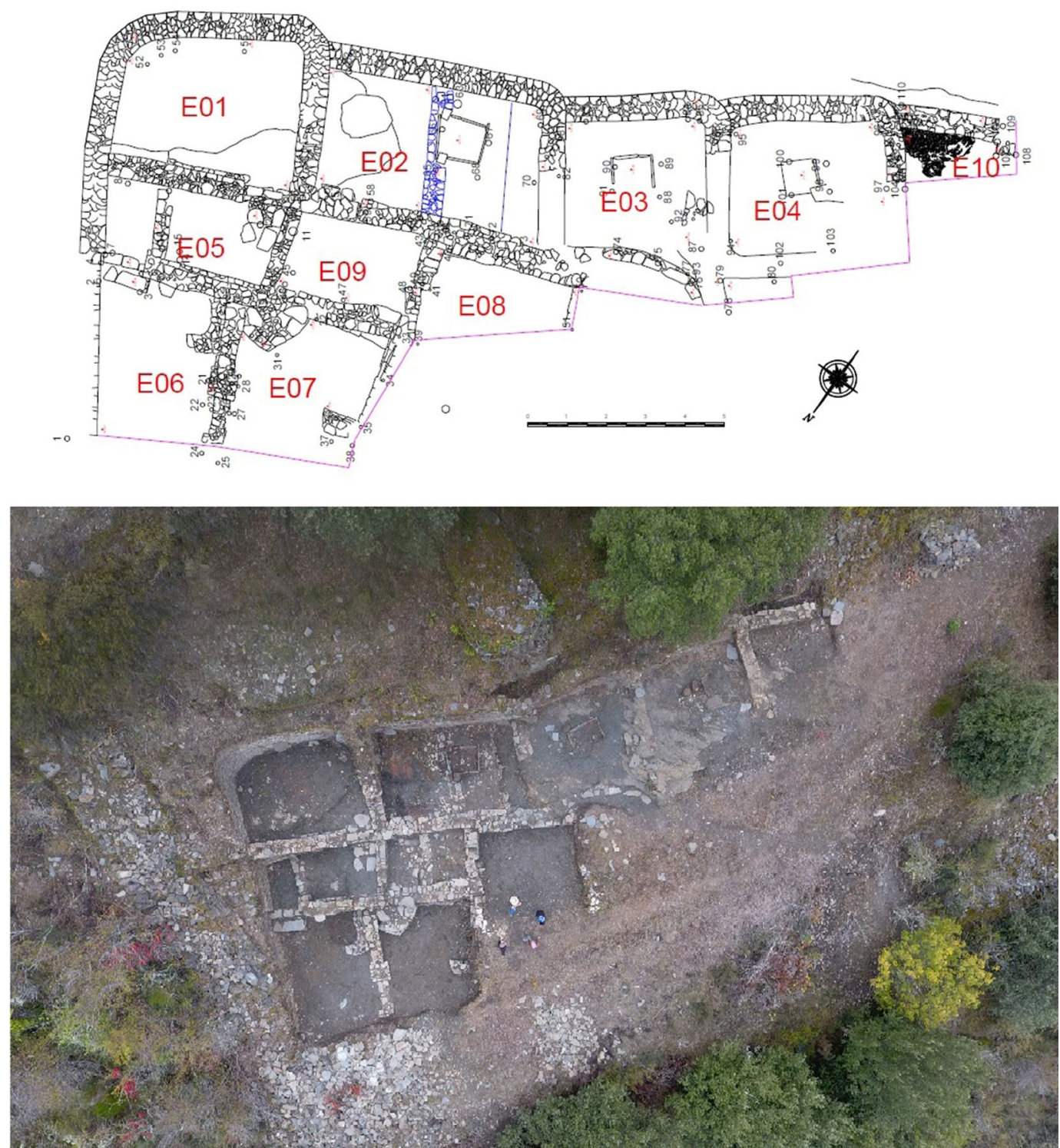

Figura 5: Planimetría del sector A. Dibujo de Santiago Ferrer

signinum. Del mismo modo cabe destacar que en la E09 se recuperó un pondus, lo que podría sugerir, a modo de hipótesis, la realización de tareas de hilado en esta estancia.

Por último, el tercer nivel o nivel inferior estaría configurado a partir de dos espacios (E06 y E07), sin pavimento documentado, y divididos por un muro medianero en cuya parte central se encontraría la base de un pilar cuadrado de mayores dimensiones que el resto del muro, de unos $60 \times 60 \mathrm{~cm}$. Esto podría indicar la presencia de un espacio semicubierto o patio exterior de la vivienda. En la E06 destaca la presencia de un posible aljibe en la parte sur para recoger el agua de esta zona semicubierta. Por su parte, la E07 presenta una escalera por la que se accedería a la E09.

En definitiva, todo este sector parece reflejar la presencia de una misma unidad doméstica perfectamente articulada y organizada espacial y funcionalmente para albergar a una o dos familias. Aunque habrá que contrastar con futuras excavaciones, se puede tomar por el momento este sector como el paradigma de una unidad doméstica en el sitio, de tal forma que entendemos que la parte doméstica del yacimiento de O Castelo estaría configurada a partir de unidades similares. Así, $\mathrm{y}$ aunque son estimaciones que conviene tomar con precaución, podemos hacer un cálculo aproximado de un máximo de 30 unidades domésticas, lo que equivaldría a una potencial población de 150-250 habitantes viviendo de forma contemporánea. Esto sería coherente para lo que se conoce para otros sitios similares y mejor conocidos, caso del cercano yacimiento de Santomé (Ourense) (Rodríguez González y Xusto Rodríguez, 2019) o de El Castillón (Santa Eulalia de Tábara, Zamora) (Sastre y Catalán, 2012). Así mismo, este espacio indicaría un alto nivel de planificación urbanística, que implicaría la presencia de poblaciones que, lejos de realizar ocupaciones temporales e inestables, pretendían mantener un cierto grado de estabilidad. 

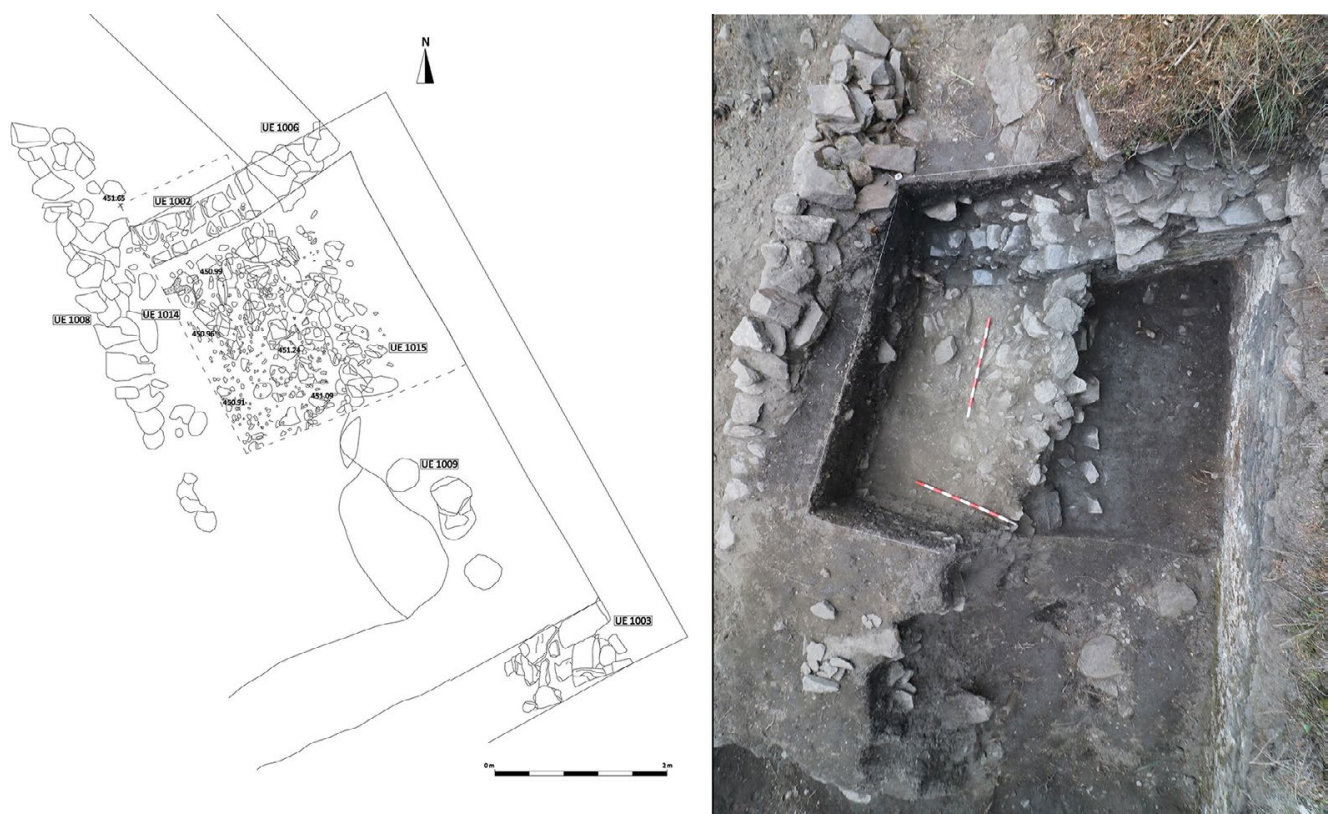

Figura 6: Planimetría de la excavación del sector B

\subsection{SeCtor B}

El Sector B se encuentra en la parte suroriental del yacimiento, en la misma plataforma en la que está construido el sector A. Este espacio fue intervenido por primera vez durante los años 60 ó 70 del pasado siglo, dejando al descubierto un paramento con restos de mortero de cal pintado. Su exposición fue el motivo principal para la realización de un sondeo arqueológico en 2019, que agotó la estratigrafía hasta los niveles de ocupación de la estructura.

Por el momento se ha podido analizar una única estructura de $30 \mathrm{~m}^{2}$, pero que, por la información disponible, estaría acompañada por diversas estructuras adyacentes tanto al noroeste como al sureste (Fig. 6).

La estructura documentada era conocida como la «casa romana», llamada así por la presencia de un destacado mortero de cal pintado en las paredes. Se trata de una estructura rectangular de $6 \times 3 \mathrm{~m}$ aproximadamente, de una única estancia construida de forma similar al resto de estancias en el sector A, a través de mampuesto y sillarejo ligeramente escuadrado de material local unido mediante barro. La secuencia estratigráfica documentada (ver Fig. 7) permitió diferenciar una única fase de ocupación situada, como veremos a través de las dataciones radiocarbónicas y del material arqueológico, entre los siglos IV e inicios del $\mathrm{V}$, seguida de un dilatado proceso de abandono con distintos episodios de derrumbe (UEs 1014 y 1016) asociados a distintos depósitos (UEs 1015 y 1017) donde se localizó el grueso de los materiales arqueológicos. Tras estas fases, y en un momento todavía indeterminado de época post-medieval, se documentaron las primeras instalaciones de viñedos en la zona - que por el material vidriado datamos preliminarmente en torno al siglo XVI-, seguido de distintos episodios subactuales que incluyen la excavación del grupo de Os Escarbadores.

Uno de los aspectos más destacados de esta estructura es la presencia de un pavimento de opus signinum (UE 1020) en perfecto estado de conservación. En este caso se pudo determinar con cierto grado de seguridad que la techumbre sería a un agua y constituida por lajas de pizarra unidas mediante grapas, un sistema constructivo común al entorno, así como documentado en otros yacimientos en cronologías similares, como Elviña o Cidadela (Bello Diéguez, 2018; Sánchez Pardo et al., 2020). Si bien las limitaciones del sondeo impiden certificar la funcionalidad de este espacio, la presencia del opus signinum así como del mortero de cal sugerirían que nos encontraríamos con otro sector doméstico. Sin embargo, la escasez de material documentado, sobre

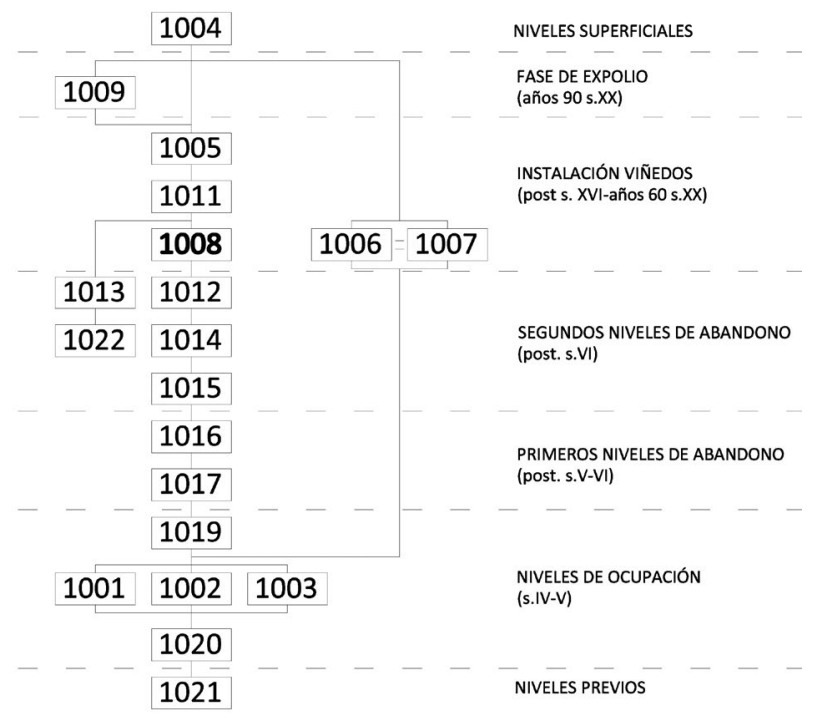

Figura 7: Matriz Harris del sector B 
todo vinculado a cerámicas de almacenamiento, así como la alta presencia de escorias en los primeros niveles de abandono sugerirían, por un lado, un proceso de abandono dilatado en el tiempo en el que los moradores de la estructura así como sucesivas expoliaciones pudieron llevarse el grueso del material presente en la estancia — de ahí la escasa y fragmentada cerámica documentada - y, por otro, la potencial presencia de actividades metalúrgicas en el entorno cercano de esta estructura o su uso, en los últimos momentos, como almacén o incluso basurero de tales actividades.

\section{DATACIONES RADIOCARBÓNICAS}

Uno de los objetivos principales de las recientes intervenciones en el yacimiento de $\mathrm{O}$ Castelo era poder datar con un cierto grado de precisión las estructuras del sitio. La intervención sobre este tipo de ocupaciones en el noroeste peninsular se ha caracterizado por la aplicación de ciertos determinismos historiográficos que los han insertado, en ocasiones de forma errónea, en períodos históricos muy dilatados que impiden su contextualización rigurosa (Tejerizo García, 2020). Con el objetivo de poder aquilatar la secuencia de ocupación anteriormente documentada, se realizaron dos dataciones radiocarbónicas a partir de material óseo (ambos de ovicaprinos) recuperado en las últimas intervenciones en el sitio. Los resultados de estas dataciones se resumen en la tabla siguiente (Figs. 8 y 9).

Como se puede observar, ambas dataciones, aunque coherentes entre sí, proporcionan rangos especialmente amplios, sobre todo teniendo en cuenta el tipo de material óseo datado, que estaría indicando el momento de muerte del animal en cuestión y, en consecuencia, un momento de deposición posterior no muy alejado en el tiempo. Esto implica, por un lado, la necesidad de hacer más dataciones en el futuro para aquilatar estas amplias horquillas y, por otro, el analizar las dataciones en términos contextuales y estratigráficos.

Así, la primera de las dataciones (Beta-548117) se realizó sobre un resto óseo documentado en un estrato

\begin{tabular}{|c|c|c|c|c|c|}
\hline $\begin{array}{c}\mathbf{N}^{\circ} \\
\text { MUESTRA }\end{array}$ & SIGLA & CONTEXTO & DATACIÓN & $\begin{array}{l}\text { CAL. 1 SIGMA } \\
(68,2 \% \text { prob. })\end{array}$ & $\begin{array}{c}\text { CAL. } 2 \text { SIGMAS } \\
(95,4 \%)\end{array}$ \\
\hline Beta -548117 & $\begin{array}{l}\text { VDS'19-1017- } \\
15\end{array}$ & $\begin{array}{l}\text { SECTOR B. UE 1017: } \\
\text { nivel inmediatamente } \\
\text { superior al opus signinum } \\
\text { (UE 1020) }\end{array}$ & $1770 \pm 30 \mathrm{BP}$ & $\begin{array}{l}274-330 \text { cal AD } \\
(42,5 \%) \\
230-264 \text { cal AD } \\
(25,7 \%)\end{array}$ & $\begin{array}{l}206-345 \text { cal AD } \\
(85,6 \%) \\
138-200 \text { cal AD }(9,8 \%)\end{array}$ \\
\hline Beta -548118 & VAL 19-H9-F1 & $\begin{array}{l}\text { SECTOR A. Nivel } \\
\text { de abandono de la } \\
\text { Habitación } 9 .\end{array}$ & $1690 \pm 30 \mathrm{BP}$ & $\begin{array}{l}332-398 \text { cal AD } \\
(68,2 \%)\end{array}$ & $\begin{array}{l}318-416 \text { cal AD } \\
(79,1 \%) \\
256-299 \text { cal AD } \\
(16,3 \%)\end{array}$ \\
\hline
\end{tabular}

Figura 8: Dataciones radiocarbónicas

Número de laboratorio Beta-548117

Edad radiocarbónica convencional $1770 \pm 30 \mathrm{BP}$

$95.4 \%$ de probabilidad

(85.6\%) $206-345 \mathrm{Cal} A D$

(9.8\%) $138-200 \mathrm{Cal} \mathrm{AD}$

$68.2 \%$ de probabilidad

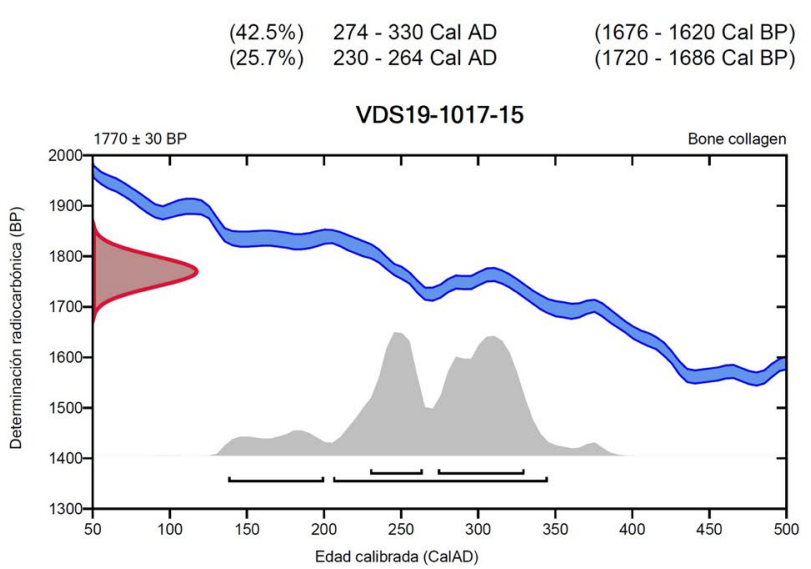

Número de laboratorio Beta-548118

Edad radiocarbónica convencional $1690 \pm 30 \mathrm{BP}$

95.4\% de probabilidad

(79.1\%) $318-416 \mathrm{Cal} \mathrm{AD}$

(1632 - 1534 Cal BP) (1694 - 1651 Cal BP)

$68.2 \%$ de probabilidad

(68.2\%) $\quad 332-398 \mathrm{Cal}$ AD

(1618 - 1552 Cal BP)

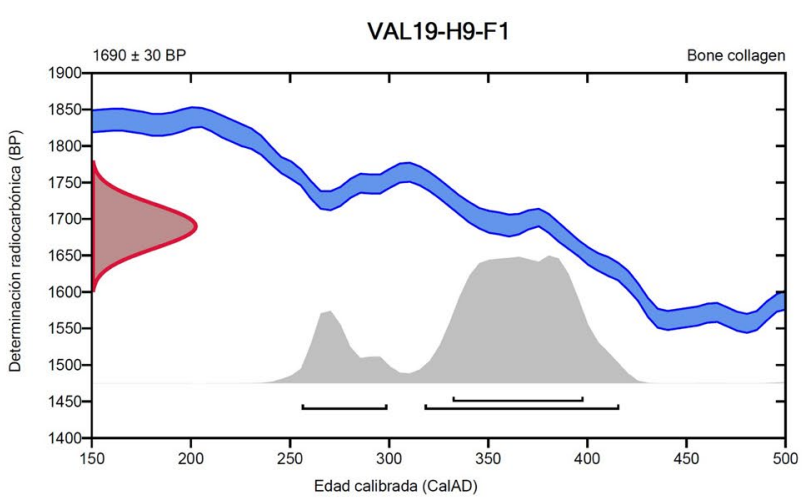

Figura 9: Dataciones radiocarbónicas 
asociado a los primeros momentos de abandono del sector B - concretamente, en la UE 1017, caracterizada como un depósito en contacto directo con el opus signinum de la estancia-, y en contexto estratigráfico con material cerámico que podemos datar a partir de la segunda mitad del s. IV d. n. e., con especial mención a una TSHT con decoración del segundo estilo Mayet. De esta manera, habría que tomar entonces la última horquilla de esta datación (mediados de esa centuria) como la más probable para la muerte del animal.

Algo similar ocurre con la segunda datación (Beta548118) extraída de los estratos de abandono de la estancia H9 y en contexto con cerámicas engobadas de época tardoimperial, datadas a partir de la cuarta centuria (Alcorta Irastorza y Bartolomé Abraira, 2012) así como de una moneda de Constancio datada a mediados de esa misma centuria (Fig. 12). En consecuencia, ambas dataciones habría que insertarlas en este momento post quem de mediados de la cuarta centuria como la más probable, si bien no se puede descartar categóricamente por el momento una cronología anterior.

\section{LA CULTURA MATERIAL EN O CASTELO}

En este apartado se presentará una síntesis de resultados del estudio de los diferentes materiales arqueológicos documentados. Dividiremos esta sección en cuatro apartados según el tipo de material: cerámica, monedas, restos faunísticos y otros materiales.

\subsection{MATERIALES CERÁMICOS}

En este apartado únicamente haremos referencia al conjunto de materiales cerámicos documentados en las dos intervenciones más recientes y a las producciones que proporcionen información adicional a lo ya conocido sobre el yacimiento. A este material hay que incluir un conjunto de 4663 fragmentos depositados en el concello de O Barco de Valdeorras que fueron objeto de un estudio preliminar y al cual remitimos (Tejerizo García, Scaro et al., 2019).

En total, en las recientes intervenciones se registraron 232 fragmentos con un peso total de 6904 gr. Como ya se ha mencionado, el grueso de este material proviene de estratos asociados a los momentos de abandono de las estancias excavadas $(75,4 \%)$, siendo el resto fragmentos cerámicos localizados en superficie o en tareas de limpieza de las estancias $(24,6 \%)$.

Al igual que el anterior material cerámico estudiado del yacimiento, el análisis realizado partió de un reconocimiento y diferenciación macroscópica de cada una de las producciones presentes en el conjunto. Así, el objetivo era distinguir las diferentes Cadenas Tecnológico-Operativas (CTO), esto es, los diferentes procesos completos, la serie de gestos y técnicas que llevan una materia, en este caso la arcilla, hasta su estado final, la cerámica, prestando atención a cada uno de los elementos constitutivos de la misma y que aporten información relevante sobre estos procesos (Lemonnier, 1986; Orton et al., 1997). En nuestro caso, fundamentalmente se atendió a la tecnología, al grado de depuración de la arcilla, el tipo de cocción y coloraciones finales. Una vez diferenciadas las producciones, éstas eran cuantificadas siguiendo el sistema de doble registro proveniente del ámbito anglosajón: el número de fragmentos y el peso en gramos. Esta cuantificación permite analizar la representación de una producción dentro del conjunto total, aspecto esencial para determinar, por ejemplo, la datación de los conjuntos en el período que aquí nos ocupa (Adroher Auroux et al., 2016; Vigil-Escalera, 2006).

Así, las producciones documentadas y sus características se resumen en la tabla siguiente (Fig. 10).

Como se puede observar, el grueso de las producciones cerámicas documentadas corresponde a producciones engobadas lucenses, cerámicas a torno oxidantes de pastas semidepuradas (CCRB) y producciones reductoras a torno (TRB), lo que es coherente con los resultados obtenidos en el análisis del material proveniente de las excavaciones antiguas en el sitio (Tejerizo García, Scaro et al., 2019). Entre el material más diagnóstico de las intervenciones más recientes (Fig. 11) cabe destacar la presencia de un fragmento de Terra Sigillata Hispánica Tardía (VDS’19/1004/19) con decoración de círculos secantes a compás y espigas características del segundo estilo Mayet o grupo 2a de Vigil-Escalera (Vigil-Escalera, 2015). Asimismo, una decoración muy significativa documentada son los grafitos. Ya en las intervenciones antiguas se hacía mención a algún fragmento de cerámica «con la firma 'M A M'», que indicaba la presencia de esta forma decorativa (Tejerizo García, Scaro et al., 2019). En el conjunto analizado se documentó un fragmento sobre una superficie engobada en el que se puede leer «[N] IANI» - lo que no descarta que sea la misma cerámica referenciada en el inventario pero con una transcripción errónea- Igualmente, en un pequeño fragmento de producción oxidante, en la zona del labio, se pueden leer las letras «NI». En este sentido, destaca una forma completa de jarra de cuerpo fusiforme con borde en «L», monoansada y engobada en el exterior de color rojizo, decoración con líneas verticales espatuladas sobre el cuello, fondo plano correspondiente al tipo EJ 1 de Alcorta Irastorza (2001) encuadrable a partir del siglo III que presenta en el cuello un grafiti: SILVANI VAL (VDS'19/H9). Estos grafitos se hicieron después de la cocción de la cerámica (conocidos como grafitos post cocturam) y, por lo tanto, no formaron parte del proceso de producción de la cerámica. Debido a su terminación es muy posible que haga referencia a nombres en genitivo, por lo que entrarían dentro de la categoría de «inscripciones nominales» cuya función principal «suele ser la de identificar al propietario de la pieza» y que son muy comunes en todo el período entre el s. II y el V d. n. e. (Ozcáriz Gil, 2010). 


\begin{tabular}{|c|c|c|c|c|c|}
\hline PRODUCCIÓN & DESCRIPCIÓN & FRAG. & \%FRAG & $\begin{array}{l}\text { PESO } \\
\text { (gr) }\end{array}$ & $\%$ PESO \\
\hline TSHT & Terra sigillata Hispánica Tardía & 13 & 5,6 & 47 & 0,6 \\
\hline CIS & $\begin{array}{l}\text { Cerámica Imitación de Sigillata (CIS). Normalmente con } \\
\text { presencia de barnices color ocre y avellanas con desgrasantes de } \\
\text { pequeño y mediano tamaño de cuarzo y mica plateada. }\end{array}$ & 3 & 1,3 & 46 & 0,6 \\
\hline CCRA & $\begin{array}{l}\text { Cerámica a torno rápido y cocción oxidante con pastas bien } \\
\text { depuradas con desgrasantes de mediano tamaño de cuarzo. }\end{array}$ & 7 & 3 & 113 & 1,6 \\
\hline CCRB & $\begin{array}{l}\text { Cerámica a torno rápido (con un mínimo porcentaje de piezas a } \\
\text { torno lento) y cocciones mixtas (tendente a oxidantes) de pastas } \\
\text { poco depuradas con desgrasantes de mediano y gran tamaño de } \\
\text { cuarzo, mica, mica plateada y chamota. }\end{array}$ & 47 & 20,2 & 1262 & 18,3 \\
\hline CCRC & $\begin{array}{l}\text { Cerámica a torno rápido y cocciones oxidantes o mixtas de } \\
\text { pastas semidepuradas con desgrasantes de mediano tamaño de } \\
\text { cuarzo y mica. }\end{array}$ & 17 & 7,3 & 354 & 5,1 \\
\hline Engobada & $\begin{array}{l}\text { Producciones a torno rápido de cocciones mixtas, normalmente } \\
\text { oxidante al exterior y reductora al interior. Presencia de } \\
\text { abundantes desgrasantes de mica plateada de mediano y gran } \\
\text { tamaño. }\end{array}$ & 58 & 25 & 584 & 8,4 \\
\hline Paredes finas & $\begin{array}{l}\text { Producciones a torno de pastas blancas semidepuradas o } \\
\text { depuradas con desgrasantes de pequeño tamaño de cuarzo, } \\
\text { mica plateada y chamota con grosores muy pequeños }(<5 \\
\text { mm). Algunas aparecen pintadas con motivos en ocre (ondas } \\
\text { normalmente) e incisiones. }\end{array}$ & 1 & 0,4 & 8 & 0,1 \\
\hline Ánfora & $\begin{array}{l}\text { Cerámica de características muy similares a la CCRB pero } \\
\text { asociadas a formas de ánfora, caracterizadas por los grandes } \\
\text { tamaños y paredes muy gruesas en pastas de cocción oxidante } \\
\text { muy poco depuradas. }\end{array}$ & 13 & 5,6 & 2346 & 34 \\
\hline TRA & $\begin{array}{l}\text { Cerámica a torno rápido y cocción reductora, bien depurada con } \\
\text { desgrasantes medianos y pequeños de cuarzo y mica plateada de } \\
\text { buena calidad. }\end{array}$ & 1 & 0,4 & 7 & 0,1 \\
\hline TRB & $\begin{array}{l}\text { Cerámica a torno rápido (con un mínimo porcentaje de piezas } \\
\text { a torno lento) y cocción reductora, escasamente depurada con } \\
\text { desgrasantes de mediano y gran tamaño }(>5 \mathrm{~mm}) \text { de chamota, } \\
\text { cuarzo y mica plateada y dorada. }\end{array}$ & 36 & 15,5 & 580 & 8,4 \\
\hline TRC & $\begin{array}{l}\text { Cerámica a torno rápido, semidepuradas y con desgrasantes de } \\
\text { mediano tamaño de cuarzo y mica plateada. Variante de pastas } \\
\text { muy jabonosas. }\end{array}$ & 20 & 8,6 & 257 & 3,7 \\
\hline \multirow[t]{2}{*}{ Moderna } & Cerámicas post-medievales y vidriadas & 16 & 6,8 & 1300 & 18,8 \\
\hline & TOTAL & 232 & & 6904 & \\
\hline
\end{tabular}

Figura 10: CTO documentadas en el yacimiento de O Castelo

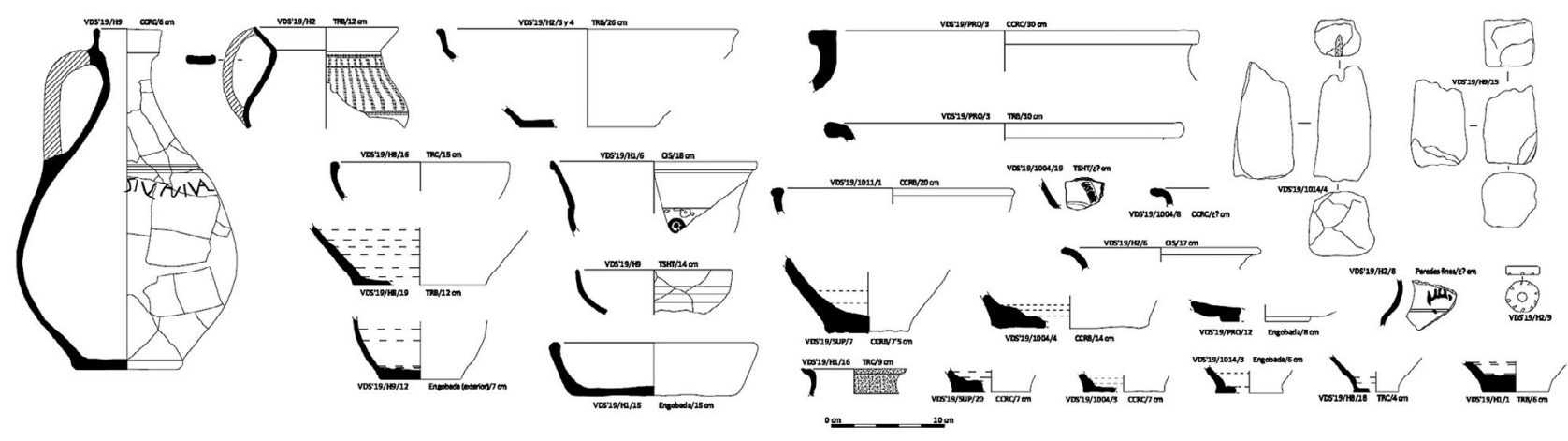

Figura 11: Cerámicas de las excavaciones recientes en O Castelo

En esta misma H9 también se documentó un conjunto de fragmentos de ánfora (VDS'19/H9/16), si bien no se pudo determinar la tipología concreta, al faltar elementos diagnósticos de la misma. También cabría destacar una jarrita monoansada de cocción reductora con líneas de bruñidos verticales (VDS'19/H2) que podría datarse en un intervalo entre los siglos IV y VI d. n. e., por comparación con otros contextos mejor 
conocidos, como el de Viladonga (Castro de Rei, Lugo) (Tejerizo García et al., 2019). Igualmente cabría destacar la presencia de un cuenco carenado de cocción reductora (VDS'19/H2/3 y 4) encuadrable en la quinta centuria (Vigil-Escalera, 2006). Por último, y como parte del material cerámico, mencionar dos pondera, uno documentado en el sector A (VDS'19/H9/15) y otro en el sector B (VDS'19/1014/4).

Como un elemento a destacar por su rareza dentro del conjunto, en los niveles superiores de la E02 se documentó un pequeño conjunto de fragmentos de galbo procedentes de una vasija de almacenamiento de grandes dimensiones de cocción plenamente reductora y pastas poco depuradas pero duras y bien cocidas, realizadas a torno, que presentaba una decoración de cordón digitado (VAL'19/H2/14). El tipo de producción, con pastas «gris perla», y decoración de la cerámica permitirían encuadrarla dentro de un momento tardomedieval o incluso de época moderna, a tenor de los paralelos conocidos en el noroeste peninsular (César Vila et al., 2010; Suárez Otero et al., 1989). El escaso estudio de la cerámica medieval en el entorno de Valdeorras y la ausencia del borde del recipiente, no permite afinar más esta datación, pero existen recipientes medievales de gran tamaño, pastas gris perla y cordones digitados identificados como grandes cántaros para líquidos, en el entorno de Santiago de Compostela, encuadrables en época plenomedieval (Alonso Toucido, 2015: 246), en este caso la factura a torno y calidad de sus pastas hace que nos decantemos por la Baja Edad Media o Temprana Edad Moderna. Esto implicaría la reocupación de este espacio durante este período, quizá en relación con la implantación de viñedos en la zona.

\subsection{LAS MONEDAS: UN ANÁLISIS PRELIMINAR}

Ya desde las primeras intervenciones en el yacimiento de O Castelo se documentaron monedas de época romana. La primera publicación que hace referencia a numerario de este período fue la de Méndez Revuelta ${ }^{3}$, donde se comenta que entre el material asociado al sitio se incluía la aparición de monedas acuñadas en «Cascantum» (Cascante, Navarra) y «dos bronces de Constantino I» (Méndez Revuelta, 1974-1975: 299, nota 295). Dos años más tarde se publica una noticia en el periódico La Región en la que se lista un conjunto de 13 monedas, si bien no se especifica su contexto concreto de localización. Finalmente, en la intervención llevada a cabo en agosto de 2019 se recuperaron en contexto estratigráfico un conjunto de ocho monedas,

\footnotetext{
3. Si excluimos un trabajo de Bouza Brey en el que daba noticia de dos monedas de época sueva que él atribuía al yacimiento de Valencia do Sil en cuanto posible ceca (Bouza Brey, 1953). Afirmación que dados los datos conocidos ahora tanto del asentamiento como de la distribución de la moneda de época sueva, cabría poner en duda (Díaz Martínez, 2011).
}

todas ellas localizadas en el sector A. Hay que subrayar aquí que, debido a la historiografía del sitio y la intensa actividad de expoliadores que han venido actuando en la zona es muy posible que el conjunto de monedas exhumado fuera mayor, si bien en paradero desconocido. Una descripción detallada de este conjunto de 21 monedas se puede ver en la tabla siguiente (Fig. 12).

Como se puede comprobar, se trata de un conjunto de monedas datadas entre finales del s. I y finales del s. IV d. n. e. En porcentaje, el $90 \%$ de ellas pertenecen a los s. III y IV con un número igual de monedas (nueve) acuñadas en cada uno de ambos siglos, porcentajes similares a lo conocido para otros contextos similares, como Santomé o Viladonga (Durán Fuentes, 2009; Varela Barrios et al., 1997). Cabe destacar que en todos los contextos estratigráficos documentados en el sector A han aparecido monedas datadas a finales del s. III o, normalmente, en el siglo IV d. n. e., a excepción de un sestercio de Domiciano (90-91 d. n. e.), localizado, sin embargo, junto con un antoniniano del s. III. Teniendo en cuenta que todo este sector debió de estar ocupado contemporáneamente, al menos en gran parte de las fases antiguas, esto marcaría una datación post quem de ocupación del sitio en torno a mediados de la cuarta centuria. Esta fecha post quem podría llevarse hasta finales del s. IV por la aparición de una moneda de Magno Clemente Máximo (383-388 d. n. e.), si bien con la precaución de que no se localizó en contexto. En cualquier caso, estas fechas serían coherentes con las dataciones radiocarbónicas.

La aparición de conjuntos de monedas de momentos y tipologías diferentes en los mismos contextos estratigráficos es un fenómeno muy común asociado a las ocupaciones fortificadas a partir del s. IV d. n. e. (Cepeda, 1988). El caso más cercano a O Castelo sería el de Penadominga (Bendilló, Lugo), yacimiento habitualmente datado a partir de la quinta centuria (Fernández Pereiro et al., 2017; Sánchez Pardo, 2010a) y donde se localizó un conjunto de 90 monedas, de las cuales 88 pertenecen al siglo IV d. n. e. y dos ejemplares al siglo II d. n. e., lo que llevó a Cepeda a datar la circulación de estas monedas a partir de la segunda mitad de la cuarta centuria (Cepeda, 1993: 101). Otro ejemplo significativo de este fenómeno de aparición de monedas de diferentes dataciones y tipologías en momentos datados a partir de la cuarta centuria sería Viladonga (Durán Fuentes, 2009), donde en las últimas intervenciones se documentaron varios tesorillos con acuñaciones desde el siglo I hasta finales del IV d. n. e. dentro del mismo contexto estratigráfico que se podía fechar ya en la quinta centuria (Tejerizo García, Rodríguez González et al., 2019).

Este fenómeno monetario de ocultación de tesorillos y conjuntos de monedas en estos momentos tardíos de época romana es muy común en la península ibérica, y ha sido interpretado en el contexto de un período de inseguridad económica en el que las élites locales y territoriales harían acopio de todo el numerario disponible que incluiría monedas de vieja circulación 


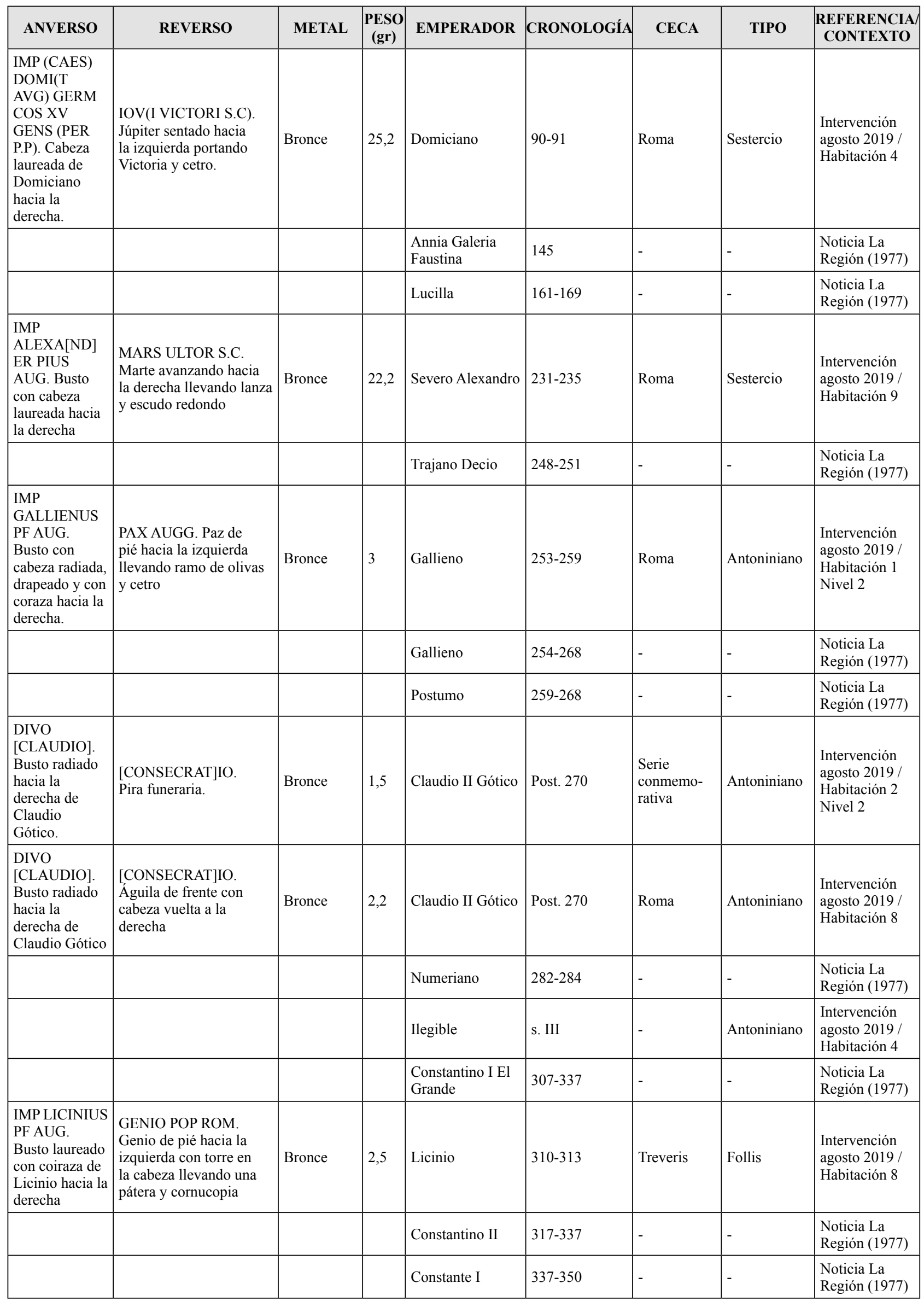




\begin{tabular}{|c|c|c|c|c|c|c|c|c|}
\hline $\begin{array}{l}\text { [CO]NSTANTI } \\
\text { VS PF } \\
\text { A[VG]. Busto } \\
\text { laureado hacia } \\
\text { la derecha d } \\
\text { Contancio } \\
\text { con coraza y } \\
\text { paludamentum } \\
\end{array}$ & $\begin{array}{l}\text { VICTORI[AEDDAVGG] } \\
\text { QNN. Dos Victorias } \\
\text { aladas, confrontadas y } \\
\text { llevando corona. }\end{array}$ & Bronce & 1,5 & Constancio & $341-346$ & Lugdunum & AE4 & $\begin{array}{l}\text { Intervención } \\
\text { agosto } 2019 \text { / } \\
\text { Habitación } 9\end{array}$ \\
\hline \multirow[t]{4}{*}{$\begin{array}{l}\text { DN } \\
\text { DECENTIUS } \\
\text { NOB CAES. } \\
\text { Busto con } \\
\text { cabeza } \\
\text { desnuda hacia } \\
\text { la derecha de } \\
\text { Decentio. }\end{array}$} & $\begin{array}{l}\text { [VICT]ORIAE DD } \\
\text { NN AUG ET CAES. } \\
\text { Dos Victorias de pié } \\
\text { confrontadas llevando } \\
\text { en el medio una corona } \\
\text { con leyenda: VOT V } \\
\text { MULT X. }\end{array}$ & Bronce & 4,1 & Decentio & $350-353$ & Lugdunum & Follis & $\begin{array}{l}\text { Intervención } \\
\text { agosto 2019/ } \\
\text { Habitación } 1 \\
\text { Nivel } 2\end{array}$ \\
\hline & & & & Magencio & $350-353$ & - & - & $\begin{array}{l}\text { Noticia La } \\
\text { Región (1977) }\end{array}$ \\
\hline & & & & $\begin{array}{l}\text { Magnus } \\
\text { Decentius }\end{array}$ & $351-353$ & - & - & $\begin{array}{l}\text { Noticia La } \\
\text { Región (1977) }\end{array}$ \\
\hline & & & & Magnus Maximus & $383-388$ & - & - & $\begin{array}{l}\text { Noticia La } \\
\text { Región (1977) }\end{array}$ \\
\hline
\end{tabular}

Figura 12: Monedas documentadas en O Castelo

-incluso altoimperiales - pero cuyo peso en metal seguiría siendo económicamente útil (Vigil-Escalera, 2015: 59 y ss.). Esto explica por qué en este tipo de conjuntos el numerario de la cuarta centuria sería el más común, dado que es el momento de mayor circulación monetaria antes de su acumulación y depósito. Por lo tanto, la datación de este tipo de contextos a través de la moneda debe ser tomada con precaución y siempre atendiendo a las dataciones post quem, debido a que el momento de deposición de estas puede ser mucho más tardío que el de su acuñación. Por lo tanto, a partir del (todavía) pequeño conjunto numerario disponible para O Castelo, habría que situar la ocupación del sector A dentro de la segunda mitad del s. IV d. n. e. sino en los últimos momentos de esa misma centuria o, teniendo en cuenta la posible posterior deposición de este numerario, ya dentro de la quinta centuria.

\subsection{LA INFORMACIÓN ZOOARQUEOLÓGICA}

Para el estudio zooarqueológico se ha dispuesto de materiales recuperados en una limpieza del año 1994 (Fernández Rodríguez, 2000) y en la intervención más reciente de 2019 (Fernández Rodríguez, 2020). En las referencias indicadas se recogen de manera detallada los criterios metodológicos utilizados en el análisis de estas dos muestras, cuyo volumen es bastante modesto: 120 restos en la limpieza de 1994 y 75 en la de 2019, correspondientes prácticamente en su totalidad a los estratos de abandono de las estancias del sector A. Aun separadas por más de dos décadas, la procedencia de los materiales de una misma zona del yacimiento y la documentación de un registro arqueológico similar, permiten hacer una valoración conjunta.

Aun cuando es un conjunto de restos reducido, la diversidad de taxones identificados es amplia, incluyendo tanto especies con interés alimenticio como otras que de manera habitual no lo son, siendo valoradas para otros fines que pueden ir desde tareas de ayuda (custodia) hasta animales de compañía (Figs. 13 y 14).

Si consideramos el origen deposicional de la muestra, atendiendo al tipo de grupos tafonómicos presentes (Gautier, 1987), el primero de los mismos, en el que se incluyen los restos de desechos alimenticios, englobaría prácticamente todo el conjunto analizado, excluyéndose únicamente los restos de caballo, perro y gato, así como también los de ciervo, al no poder asegurar su procedencia de ejemplares cazados.

Las evidencias de manufacturas óseas (Grupo 2) están representadas por un fragmento de asta de cérvido

\begin{tabular}{|c|c|c|c|c|}
\hline & NR & $\%$ & $\mathbf{P}$ & $\%$ \\
\hline Equus caballus & 1 & 0,96 & 15,0 & 1,10 \\
\hline Bos taurus & 42 & 40,39 & 863,0 & 63,34 \\
\hline Ovis aries & 3 & \multirow[b]{3}{*}{38,46} & 30,7 & \multirow[b]{3}{*}{19,10} \\
\hline Ovis aries / Capra hircus & 32 & & 183,9 & \\
\hline Capra hircus & 5 & & 45,6 & \\
\hline Sus domesticus & 7 & \multirow[b]{2}{*}{15,39} & 165,1 & \multirow[b]{2}{*}{15,54} \\
\hline Sus sp. & 9 & & 46,6 & \\
\hline Canis familiaris & 3 & 2,88 & 9,4 & 0,69 \\
\hline Felis catus & 2 & 1,92 & 3,1 & 0,23 \\
\hline Cervus elaphus* & (3) & & $(85,5)$ & \\
\hline Determinados & 105 & 53,85 & 1447,9 & 73,67 \\
\hline Indeterminados & 90 & 46,15 & 517,4 & 26,33 \\
\hline TOTAL & 195 & & 1965,3 & \\
\hline
\end{tabular}

Figura 13: Macromamíferos distribución de los restos 


\begin{tabular}{|c|c|c|c|c|c|c|c|c|c|c|}
\hline & E.c. & B.t. & O.a. & $\mathrm{O} / \mathrm{C}$ & C.h. & S.d. & S.sp. & C.f. & F.c. & C.e. \\
\hline Asta & & & & & & & & & & 3 \\
\hline Neurocráneo / clavija ósea & & 9 & & 2 & & 2 & & & & \\
\hline Maxilar + dientes aislados & & & & 6 & & 2 & 3 & & & \\
\hline Mandíbula + dientes aislados & 1 & 5 & & 7 & 1 & 3 & 4 & & 1 & \\
\hline Atlas & & & & & & & & & 1 & \\
\hline Vértebra cervical & & & & 2 & & & & & & \\
\hline Vértebra torácica & & 1 & & 2 & & & 1 & & & \\
\hline Vértebra lumbar & & 2 & & 2 & & & & & & \\
\hline Costillas & & 6 & & 3 & & & & & & \\
\hline Húmero & & 3 & 1 & 1 & & & & & & \\
\hline Radio & & & & & 1 & & & & & \\
\hline Ulna & & 2 & & & & & & & & \\
\hline Carpales & & 1 & & & & & & & & \\
\hline Metacarpo & & 1 & & & 1 & & & & & \\
\hline Metacarpo II & & & & & & & & 1 & & \\
\hline Metacarpo III & & & & & & & 1 & & & \\
\hline Metacarpo V & & & & & & & & 1 & & \\
\hline Pelvis & & 1 & & & & & & & & \\
\hline Fémur & & & & 2 & & & & & & \\
\hline Tibia & & 1 & 2 & 3 & & & & & & \\
\hline Calcáneo & & 2 & & & & & & & & \\
\hline Metatarso & & 3 & & 2 & & & & & & \\
\hline Metatarso IV & & & & & & & & 1 & & \\
\hline Metapodio distal ind. & & 1 & & & & & & & & \\
\hline Falange primera & & 2 & & & 2 & & & & & \\
\hline Falange segunda & & 1 & & & & & & & & \\
\hline Falange tercera & & 1 & & & & & & & & \\
\hline Total & 1 & 42 & 3 & 32 & 5 & 7 & 9 & 3 & 2 & 3 \\
\hline
\end{tabular}

Figura 14: Valencia do Sil - Macromamíferos distribución, por taxón, de las partes anatómicas representadas

(Cervus elaphus) con evidencia de aserrado y otros dos que, si bien no presentan ninguna marca que permita señalar con seguridad un procesado antrópico, también parecen corresponder a desechos de materia prima bruta alterados (rotos) tras ser descartados.

Con animales que no han sido objeto de consumo alimenticio (Grupo 3) se identifican los restos de caballo (Equus caballus), perro (Canis familiaris) y gato doméstico (Felis catus). Aun cuando no se pueda excluir de forma categórica un posible consumo de estas especies, en principio no se ha constatado en registros coetáneos del noroeste (Fernández Rodríguez, 2000; 2003), ni tampoco hay marcas en este material que sugiera un procesado con estos fines.

Vacuno y ovicaprinos se constituyen como los taxones mejor representados, con números de restos similares pero con un lógico predominio del vacuno considerando su peso. Los restos de vacuno reflejan procesos de matanza de adultos, incluso posiblemente seniles valorando el desgaste de un último molar $\left(\mathrm{M}_{3}\right)$ presente, lo que sugiere el aprovechamiento de otros productos derivados (fuerza, leche, estiércol, etc.) antes de hacerlo con su carne.

Tanto ovejas como cabras han sido identificadas de manera específica, sin que sus valores permitan aceptar como definitivo el ligero predominio de las segundas. Las edades de muerte reflejadas para el ovicaprino son variadas, reconociéndose ejemplares infantiles (hasta 9 meses), juveniles (entre 9 y 24 meses) y subadultos y adultos (desde los 24 hasta más de 60 meses), si bien estos últimos no parecen haber sobrevivido hasta edades avanzadas tras integrarse en esta cohorte. La gestión de este 'rebaño mixto' parece reflejar la búsqueda de carne con el sacrificio de individuos jóvenes; pero el mantenimiento de otros hasta edades más avanzadas haría posible tanto el aprovechamiento de otros productos (leche, lana, estiércol, etc.) como los procesos de cría que asegurarían el reemplazo y el mantenimiento del rebaño.

Los suidos son el tercer grupo en representación porcentual de restos, si bien a significativa distancia de los anteriores. Entre estos restos se ha reconocido, por 
criterios biométricos (Altuna y Mariezkurrena, 2011), la presencia de ejemplares domésticos (Sus domesticus), sin que esté atestiguada la de salvajes (Sus scrofa), aunque tampoco pueda descartarse. Las edades de sacrificio se centran en torno a los dos años (desde los 12 a los 30 meses), lo habitual en los asentamientos rurales de época antigua en el noroeste (Fernández Rodríguez, 2000) y con una clara búsqueda del mejor momento para un aprovechamiento cárnico; pero también se han documentado restos que reflejan la matanza de infantiles e incluso de un cochinillo neonato; aun cuando no se haya podido concretar el seguro consumo de este último, esta actividad se relaciona de forma habitual con contextos claramente romanizados (Fernández Rodríguez, 2003).

Las demás especies representadas no aportan mucha información. Tanto los restos de cánido doméstico como los de gato proceden de ejemplares adultos, a lo que podemos añadir en el caso del primero (todos los restos podrían proceder de un mismo ejemplar) su asociación a un perro de talla mediana (unos $58 \mathrm{~cm}$ de alzada) de acuerdo con los factores propuestos por Clark (1995), que no parecen resultar muy precisos. Un único diente de équido adulto tampoco permite hacer una valoración de la gestión de esta especie.

Por último, ha sido posible reconocer la manufactura de objetos óseos en asta de ciervo a partir de un fragmento que tiene marcas de procesado antrópico, un aserrado en la zona basal de un candil, próxima a la unión con la rama. No parece desacertado considerar que otros dos fragmentos de asta se puedan identificar también con desechos de materia prima, aun cuando no conservan ningún tipo de evidencia de manipulación. Si bien el ciervo es la única evidencia directa de la presencia de especies salvajes (ya se ha indicado que el jabalí no lo está con seguridad), el que no se registre la zona de unión del asta con el cráneo no permite asegurar su procedencia de ejemplares cazados, pudiendo reflejar la recolección de cuernas de desmogue (Fernández Rodríguez y Caamaño Gesto, 1996).

Hay dos aspectos en la muestra analizada que merecen ser tenidos en cuenta: la presencia de restos bastantes grandes y la documentación de partes anatómicas no habitualmente conservadas de manera tan completa (como los cráneos), y cuya fragmentación parece estar relacionada con procesos postdeposicionales. A su vez, el que se incluyan restos de especies sin interés alimenticio, como los de équido, perro o gato, también puede resultar significativo.

En este sentido, debemos tener en cuenta que la intervención se ha llevado a cabo en una zona en la que se identifican sobre todo espacios habitacionales, que no se corresponden con lugares de depósito de desperdicios (basureros). Los restos faunísticos que suelen recuperarse en estos espacios suelen reflejar su inclusión en los suelos (durante su conformación o bien en modificaciones posteriores), predominando los huesos de dimensiones pequeñas, afectados por procesos que han provocado su fragmentación (pavimentos compactados, pisoteo o trampling, etc.).
Es interesante señalar que en la muestra analizada (Fig. 14) se han reconocido no solo piezas de grandes dimensiones, cuya localización en espacios habitacionales no es habitual ni coherente, sino también elementos de especies que no suelen ser objeto de consumo y que, en consecuencia, suelen depositarse tras su muerte en lugares alejados de las zonas de habitación. En consecuencia, no podemos descartar el que la muestra estudiada esté constituida al menos en parte por restos que se hayan depositado en un momento en que estos espacios habían perdido la función para el que habían sido concebidos, reflejando su abandono (lo que no implicaría necesariamente el total del asentamiento), y el consiguiente uso como lugar de acumulación de basuras al tiempo que se iban degradando y desmoronando las estructuras constructivas.

Si bien la muestra zooarqueológica es bastante limitada, aporta una significativa información sobre la economía y alimentación de los habitantes de O Castelo así como de un territorio y de una cronología de las cuales no hay mucha información, salvo la publicada para el yacimiento de Castro Ventosa (Díaz y Garín, 1999). Así, es importante destacar la relevancia cuantitativa de las cabañas ganaderas más comunes, como son los vacunos y los ovicaprinos, junto con presencia de suidos o de especies salvajes como el ciervo, lo que implica una diversificación de las estrategias alimentarias. Igualmente, cabe destacar que la presencia de partes anatómicas como cráneos o mandíbulas implican la manipulación y procesado dentro del propio habitat de O Castelo, lo que sugeriría que su cría y estabulación podría darse también al interior del yacimiento.

\subsection{OTROS MATERIALES DOCUMENTADOS}

Antes de finalizar el apartado de análisis de la cultura material hay que hacer referencia a los, por el momento escasos, elementos de metal no monetario. De nuevo, las diferentes intervenciones, expolios y separaciones de material llevados a cabo en el yacimiento causaron la infrarrepresentación de este tipo de objetos en el conjunto conservado. Así, por ejemplo, en un inventario realizado por el Instituto de Estudios Valdeorreses del material del yacimiento se hacía mención a objetos tales como anillos de bronce, sortijas, fíbulas y punzones que han desaparecido, fruto de los expolios posteriores a su excavación (Tejerizo García, Scaro et al., 2019).

Por lo tanto, el conjunto de elementos metálicos localizados en el yacimiento se ha visto reducido a objetos muy comunes en los contextos arqueológicos del período, tales como tachuelas, clavos o pequeños fragmentos indeterminados. Cabe mencionar, sin embargo, la aparición en la E02 del sector A de un fragmento de cuchillo de hierro del que se conserva el mango y parte del filo de una cara de $12,5 \times 3,2 \mathrm{~cm}$. Lamentablemente, el estado de oxidación del cuchillo era tan avanzado que no se pudieron realizar análisis arqueométricos para determinar el proceso de producción. 
Uno de los elementos más significativos localizados en el denominado sector B fue un amplio conjunto tanto de escorias, muy posiblemente de hierro, como de fragmentos de mena de hierro, que indicarían la realización de tareas vinculadas con la metalurgia que, a falta de análisis más detallados, probablemente estuvieran relacionados con la forja de hierro o, tal vez, de cobre. Cabe destacar que en los entornos inmediatos de O Castelo se localizan vetas y canteras tanto de un mineral como de otro.

En una publicación sobre la arqueología de la comarca de Valdeorras se recogía un capitel de mármol datado en época suevo-visigótica que, si bien se desconoce su procedencia exacta, se ha asociado al sitio de O Castelo (Rodríguez Colmenero et al., 2009), lo que justifica un estudio detallado que ayude a esclarecer esta potencial asociación (Fig. 15). El análisis que hemos realizado permite caracterizarla como una pieza de mármol tallada en un bloque cuadrangular de unos $30 \mathrm{~cm}$ aproximadamente de lado. La pieza presenta signos de erosión, y ha sido horadada en su parte superior para servir de pila de agua bendita en la iglesia parroquial de Valencia do Sil en la que se encuentra actualmente. Pese a ello, tiene un aceptable estado de conservación. A nivel decorativo estamos ante un capitel derivado del estilo corintio decorado con motivos de hojas y volutas carnosas. Sobre el cálatos troncocónico se dispone una única fila de cuatro hojas con el ápice vuelto. Entre ellas, en dos de las caras, hay unos gruesos caulículos con collarín sobre los que se generan unas hélices enroscadas hacia fuera. El ábaco es de perfil cóncavo y muy voluminoso ${ }^{4}$. A nivel general, la forma y decoración de esta pieza concuerdan con los modelos conocidos en el noroeste peninsular en época tardorromana y altomedieval, todos ellos capiteles derivados del modelo corintio (Domingo Magaña, 2011). Sin embargo, sus características concretas son peculiares y se alejan de las producciones mejor conocidas de la zona de Lugo y de la costa. En general, este carácter peculiar se hace extensivo a todas las piezas de escultura arquitectónica conocidas en la zona de Valdeorras, cuyos rasgos son marcadamente diferentes al del resto de Galicia (Rodríguez Colmenero et al., 2009). En todo caso, con la información que tenemos a día de hoy, la forma y decoración de este capitel encajan mejor en una cronología entre los siglos V y VII que en otra posterior, lo que podría sugerir, por las cronologías que se manejan para la ocupación del sitio de O Castelo, que no pertenecería a este yacimiento, sino que procedería de un potencial asentamiento posterior en el tiempo y ubicado posiblemente en las cercanías del actual núcleo de Valencia do Sil. Esta afirmación vendría reforzada por la ausencia de elementos arquitectónicos similares en las excavaciones realizadas, si bien no se descarta que pudieran aparecer en el futuro.

4. Agradecemos la valiosa ayuda de María José de la Torre Llorca en el análisis de este capitel

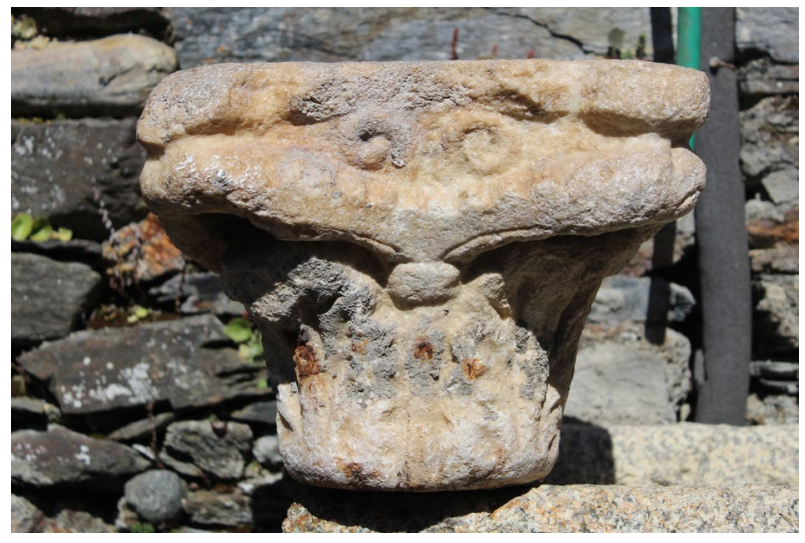

Figura 15: Capitel vinculado al asentamiento de O Castelo. Fotografía de Sputnik Labrego (https://sputniklabrego.com/)

\section{PROPUESTA DE SECUENCIA DE OCUPA- CIÓN DE O CASTELO}

La ocupación del sitio de O Castelo ha sido tradicionalmente vinculada con los momentos tardíos de presencia del Imperio Romano en la zona de Valdeorras que, hay que recordar, fue especialmente intensa en este territorio. Así, algunos autores asociaron la ocupación del sitio con las dinámicas de expansión del Imperio ya desde la primera centuria, si bien con un momento más intenso de ocupación a partir de los siglos III y IV d. n. e. (Rodríguez Colmenero et al., 2009). Por su parte, autores como Rodríguez Lovelle o López Quiroga asociaron el yacimiento de $\mathrm{O}$ Castelo con las dinámicas de inestabilidad del noroeste peninsular a partir de la invasión de los grupos de suevos, vándalos y alanos en la primera mitad del s. V. d. n. e. (López Quiroga y Rodríguez Lovelle, 1999). En esta línea, otros investigadores, como Sánchez Pardo, insertaron el contexto de $\mathrm{O}$ Castelo dentro de las transformaciones del paisaje que darían lugar a la Alta Edad Media, en un proceso de larga duración desde la cuarta centuria (Sánchez Pardo, 2010a; 2012). En cualquier caso, y como hemos visto, hasta el momento no se disponía de datos suficientes para poder hacer hipótesis fundamentadas sobre los momentos concretos de ocupación $\mathrm{y}$ abandono de este yacimiento.

En consecuencia, a partir de todos los datos presentados, se propone como fecha de ocupación más probable tanto del sector A como del sector B un momento a partir de mediados de la cuarta centuria, sin descartar la posibilidad de que la primera ocupación efectiva del sitio pudiera realizarse con anterioridad. En este sentido, cabe mencionar, aunque con cautela, la documentación de algún fragmento de sigillata altoimperial, que podría estar reflejando ocupaciones anteriores de las cuales la información es todavía muy parcial. En este sentido, una de las evidencias más interesantes de las últimas intervenciones del sector A es la documentación de, al menos, tres fases de ocupación, dos dentro del período romano y otra de época medieval 
o moderna atestiguadas en la estratigrafía y contexto de la E02 del sector A.

Más complicada es la cuestión del abandono del sitio de O Castelo, para el cual todavía no tenemos datos concluyentes. A partir de las dataciones radiocarbónicas realizadas y del análisis de material cerámico presentado, se puede sugerir el ecuador de la quinta centuria como último momento de ocupación de esta fase del yacimiento, dado que el material cerámico más tardío documentado - producciones grises decoradas mediante bruñidos, la sigillata estampillada y las cerámicas de imitación de sigillata - se podría fechar en estos momentos. De igual modo, esto debe tomarse como una hipótesis a evaluar en futuras intervenciones.

En resumen, a partir de todos los datos disponibles se propone la siguiente secuencia de ocupación para el yacimiento de O Castelo:

- Fase 1; Fase altoimperial: aunque todavía con evidencias muy escasas y dispersas, se podría sugerir una potencial fase de ocupación en un momento indeterminado de la Protohistoria o época altoimperial, que vendría atestiguada por la aparición, todavía sin contexto claro, de materiales datados en este momento, así como de vestigios como los fosos excavados en la croa, que no se articulan funcionalmente con el asentamiento vinculado a la siguiente fase.

- Fase 2; mediados del s. IV-mediados del s. V: en esta fase se produciría la principal ocupación del sitio en época antigua que implicaría, como hemos visto, la remodelación completa del entorno. El momento final de esta fase y de abandono del sitio es igualmente difícil de precisar, si bien se sugiere la mitad de la quinta centuria como el momento de abandono del sitio.

- Fase 3; ¿s. XV-XVI?-años 60 siglo XX: en un momento todavía difícil de determinar con seguridad se produciría la reocupación del sitio, probablemente vinculada a la extensión del viñedo. Esta fase de ocupación finalizaría con el abandono definitivo de los viñedos y el inicio de las intervenciones arqueológicas.

\section{O CASTELO EN EL CONTEXTO ARQUEOLÓ- GICO DEL NOROESTE PENINSULAR}

Las reiteradas intervenciones en el yacimiento de $\mathrm{O}$ Castelo produjeron la paradójica situación de contar con una batería muy importante de datos sobre un sitio conocido desde hacía tiempo pero del que poco se sabía en términos científicos. Así, podemos afirmar que este sitio es, con todo, uno de los asentamientos fortificados de época tardía más excavados de todo el noroeste peninsular, junto con otros significativos ejemplos como Viladonga o Santomé (Arias Vilas et al., 2013; Rodríguez González y Xusto Rodríguez, 2019).
Uno de los aspectos más importantes derivados de todas las intervenciones en O Castelo es su gran complejidad urbanística, fruto de una clara planificación. Como hemos podido analizar, la ocupación de este enclave estuvo lejos de ser algo casual y temporal. La fuerte inversión y esfuerzo en la creación de las grandes plataformas y en la instalación de las estructuras sugieren dinámicas de gran organización y movilización de capital económico y social, muy posiblemente vinculadas a las élites territoriales de la zona de Valdeorras, sin descartar otros potenciales agentes implicados, como élites de carácter estatal asentadas en el territorio (Tejerizo García y Canosa Betés, 2018). En este sentido, el sitio de O Castelo podría asimilarse a la tipología de asentamientos fortificados como el de Santomé (Rodríguez González y Xusto Rodríguez, 2019). Igualmente, este tipo de estructuración del paisaje y del asentamiento invitaría a pensar en una gran estabilidad en su ocupación, que implicaría una sociedad bien articulada, cuyo propósito sería ocupar este enclave durante un tiempo largo.

Los datos y análisis realizados han permitido insertarlo por primera vez dentro de unas coordenadas históricas determinadas, que, bajo la propuesta aquí realizada, se integrarían dentro de los momentos finales del Imperio Romano durante la cuarta y quinta centuria. En este período, la ocupación o reocupación de entornos fortificados en todo el norte peninsular es un hecho plenamente constatado y que ha sido vinculado con las inestabilidades políticas y económicas de finales del Imperio Romano (Quirós Castillo y Tejado Sebastián, 2012; Sánchez Pardo, 2012; Tejerizo García y Canosa Betés, 2018). En un clima de fuerte inseguridad para las élites territoriales tardoimperiales, la ocupación de estos espacios en altura relativa permitió reforzar el control de los principales recursos del entorno. En el caso de O Castelo, junto con otros sitios ocupados contemporáneamente como Santa María de Mones, Penadominga o el entorno de Quiroga (Fernández Pereiro et al., 2017), el control de vías de comunicación como la vía Nova o el propio río Sil así como el control de recursos estratégicos, como la minería (Sánchez Pardo, 2014), serían claves para entender su ocupación durante este período.

La ocupación de este tipo de espacios sería un síntoma de una fuerte reestructuración del paisaje y del anterior sistema de poblamiento, principalmente articulado en torno a las ciudades y núcleos secundarios así como de las grandes villas latifundistas y pequeñas granjas dispersas por el territorio (Pérez Losada, 2002). En el caso de Valdeorras hay varias evidencias que podrían señalar esta transformación (Rodríguez Colmenero et al., 2009), que implicaría el abandono o el cambio de funcionalidad de otros establecimientos del entorno, como sería el caso de la villa de A Cigarrosa, cuyos mosaicos podrían datarse en este momento de la cuarta centuria, pero que posteriormente sería ocupada por un cementerio de época tardorromana o incluso altomedieval (Veiga Romero, 2009). Más evidente sería 
el caso del yacimiento de A Pobra, interpretado como un núcleo secundario y que, a partir de los análisis llevados a cabo, se abandonaría en algún momento de la cuarta centuria (Soto Arias et al., 1998). Aunque seguramente en un proceso generacional, la ocupación de O Castelo mostraría esta transformación y traslado del poblamiento desde unos entornos a otros.

En este sentido, la fase principal de ocupación del sitio de O Castelo, en tanto que espacio fortificado y localizado en una altura relativa que domina el espacio circundante, se introduciría dentro de la narrativa hidaciana de los castella tutiora, en tanto que espacios de mantenimiento de las dinámicas imperiales en un momento de progresiva desintegración de sus tradicionales formas de dominio (Fernández-Pereiro, 2018; López Quiroga y Rodríguez Lovelle, 1999). Ya Hidacio mostraba para finales de la cuarta centuria, antes de la llegada de los suevos, vándalos y alanos en el 409 d. n. e., un sistema imperial en fuerte tensión en la que las élites territoriales y comunidades locales tuvieron que adaptarse mediante, por ejemplo, la ocupación de estos espacios fortificados (Candelas Colodrón, 2004). Sin embargo, los datos expuestos muestran una mayor complejidad en estas narrativas de corte determinista y catastrofista. Así, la cronología de ocupación propuesta sobrepasaría estos marcos cronológicos y mostraría una ocupación del sitio de $\mathrm{O}$ Castelo de, por lo menos, tres o cuatro generaciones, lo que implica una estabilidad más allá de los marcos de la narrativa hidaciana, introduciendo sitios como O Castelo en particular y el territorio de Valdeorras en general dentro de otro tipo de dinámicas, como la de la emergencia del reino suevo o el de la negociación de las élites territoriales con los nuevos poderes emergentes (Castellanos y Martín Viso, 2005; Díaz Martínez, 2011; Tejerizo García, 2020).

Con todo, estos deben ser considerados como los primeros resultados de un proyecto de larga duración que permitirá profundizar en cuestiones todavía por dilucidar, como la presencia de anteriores fases de ocupación en el sitio de O Castelo, la organización y distribución de las estructuras, la orientación económica específica del sitio o las condiciones de vida de la sociedad que ocupó este enclave, todo dentro de unas dinámicas históricas que, como hemos visto, aunque complejas, reflejan una apasionante historia todavía por desvelar.

\section{REFERENCIAS}

Adroher Auroux, A. M., Carreras Monfort, C., Almeida, R. de, Fernández Fernández, A., Molina Vidal, J. y Viegas, C. (2016). Registro para la cuantificación de cerámica arqueológica: estado de la cuestión y una nueva propuesta. Protocolo de Sevilla (PRCS/14). Zephyrus, LXXVIII, 87-110. DOI: https://doi.org/10.14201/zephyrus20167887110

Alcorta Irastorza, E. J. (2001). Lucus Augusti (vol. II): cerámica común de cocina y mesa hallada en las excavaciones de la ciudad. A Coruña: Fundación Pedro Barrié de la Maza.
Alcorta Irastorza, E. J. y Bartolomé Abraira, R. (2012). Muestras de cerámica engobada romana de producción local de Lucus Augusti (Lugo). En D. Bernal Casasola y A. Ribera i Lacomba (Eds.). Cerámicas hispanorromanas II. Producciones regionales (pp. 699-724). Cádiz: Universidad de Cádiz.

Alonso Toucido, F. (2015). Estudio preliminar de la cerámica del área de Santiago de Compostela en época plenomedieval. En R. Martínez Peñín y G. Cavero Domínguez (Eds.). Evolución de los espacios urbanos y sus territorios en el Noroeste de la Península Ibérica (pp. 239-252). León: Ediciones el Forastero.

Altuna, J., y Mariezkurrena, K. (2011). Diferenciación biométrica de Sus Scrofa y Sus domesticus en yacimientos arqueológicos del norte de la península ibérica. Kobie, 30, $5-22$.

Arias Vilas, F., Durán Fuentes, M. C., Bastos Bernárdez, D. y Varela Arias, E. (2013). Museo do Castro de Viladonga (Castro de Rei, Lugo). Santiago de Compostela: Xunta de Galicia.

Bello Diéguez, J. M. (2018). Bajo Imperio y Tardorromanidad en el Castro de Elviña (A Coruña). Boletín del Museo Arqueológico Nacional, 37, 131-148.

Bouza Brey, F. (1953). La ceca suevo visigoda de Valencia del Sil. Zephyrus, IV, 417-427.

Candelas Colodrón, C. (2004). O Cronicón de Hidacio. Bispo de Chaves. A Coruña: Toxosoutos.

Castellanos, S. y Martín Viso, I. (2005). The local articulation of central power in the north of the Iberian Peninsula (5001000). Early Medieval Europe, 13(1), 1-42. DOI: https://doi. org/10.1111/j.1468-0254.2005.00147.x

Cepeda, J. J. (1988). Tesorillos monetarios en el norte y noroeste de la península ibérica entre la segunda mitad del siglo IV y la primera mitad del siglo V d. C. En 25 años. Facultad de Filosogía y letras. II. Estudios de Geografía e Historia. Bilbao: Universidad de Deusto.

Cepeda, J. J. (1993). Monedas procedentes del castro de Penadominga (Bendollo, Quiroga. Lugo). Numisma, 232, 91-107.

César Vila, M., Bonilla Rodríguez, A. y López Pérez, M. C. (2010). Aportaciones al conocimiento de la cerámica producida en la última fase de la Edad Media en Galicia. En R. Martínez Peñín (Ed.). Metodología de análisis aplicada a los estudios de cerámica tardoantigua y medieval de la península ibérica (pp. 145-160). León: Universidad de León.

Clark, K. M. (1995). The later prehistoric and protohistoric dog: the emergence of canine diversity. Archeozoologia, $\operatorname{VII}(2), 9-32$.

Díaz Álvarez, I. y Garín, A. (1999). Estudio de los materiales arqueológicos de Castro Ventosa. Estudios Bercianos, 25, 74-95.

Díaz Martínez, P. C. (2011). El Reino Suevo (411-585). Tres Cantos: Akal, D.L.

Domingo Magaña, J. Á. (2011). Capiteles tardorromanos $y$ visigodos en la península ibérica (siglos IV-VIII d. C.). Tarragona: Institut Català d'Arqueologia Clàssica. 
Durán Fuentes, M. C. (2009). Moedas do Museo do Castro de Viladonga. Santiago de Compostela: Xunta de Galicia.

Fernández Fernández, A. (2014). El comercio tardoantiguo (ss. IV-VII) en el Noroeste peninsular a través del registro cerámico de la ría de Vigo. Oxford: Archaeopress. DOI: https://doi.org/10.2307/j.ctvz937ss

Fernández Fernández, A. y Bartolomé Abraira, R. (2016). Cerámicas tardoantiguas en el noroeste de la Península (Galicia y norte de Portugal): entre la importación y el artesanado local/regional. En A. Vigil-Escalera Guirado y J. A. Quirós Castillo (Eds.). La cerámica de la Alta Edad Media en el cuadrante noroeste de la Península Ibérica (siglos V-X): sistemas de producción, mecanismos de distribución y patrones de consumo (pp. 69-111). Bilbao: Universidad del País Vasco.

Fernández Ochoa, C., Morillo Cerdán, Á. y Zarzalejos Prieto, M. (Eds.). (2017). Manual de cerámica romana III. Cerámicas romanas de época altoimperial III: cerámica común de mesa, cocina y almacenaje, imitaciones hispanas de series romanas, otras producciones. Madrid: Museo Arqueológico de la comunidad de Madrid.

Fernández-Pereiro, M. (2018). Recintos fortificados en altura na costa atlátinca galega. Estudo arqueolóxico. (Tesis doctoral). Universidad de Santiago de Compostela. Santiago de Compostela. Recuperado de: http://hdl.handle. net/10347/18729

Fernández Pereiro, M., Tejerizo García, C., Rodríguez González, C., Lixó Gómez, C. y Carvajal Castro, Á. (2017). Asentamentos fortificados no interior da Gallaecia en época tardoimperial e sueva (séc. IV-VI): un achegamento a partir de varios casos de estudo. Gallaecia, 36, 129-162. DOI: https://doi.org/10.15304/gall.36.5104

Fernández Rodríguez, C. (2000). Los macromamiferos en los yacimientos arqueológicos del noroeste peninsular: un estudio económico. (Tesis doctoral inédita). Universidad de Santiago de Compostela. Santiago de Compostela.

Fernández Rodríguez, C. (2003). Ganadería, caza y animales de compañía en la Galicia romana: estudio arqueozoológico. Brigantium, 15. A Coruña: Museo Arqueolóxico e Histórico Castelo de San Antón.

Fernández Rodríguez, C. (2020). Análisis de los restos óseos de macromamíferos del yacimiento de O Castelo de Valencia do Sil (Vilamartín de Valdeorras, Ourense). Intervención 2019. Informe depositado en la Dirección Xeral de Patrimonio. Santiago de Compostela.

Fernández Rodríguez, C. y Caamaño Gesto, J. M. (1996). Utillaje óseo de castros galaico-romanos de Galicia. En A. A. Rodríguez Casal (Ed.). Humanitas: estudios en homenaxe ó Prof. Dr. Carlos Alonso del real. Santiago de Compostela: Universidade de Santiago de Compostela.

Ferrer Sierra, S. (2006). Señalización romana de las vías en el noroeste de Hispania. En I. Moreno Gallo (Ed.). Nuevos elementos de ingeniería romana: III Congreso de las Obras Públicas Romanas (pp. 67-85). Valladolid: Junta de Castilla y León.

Ferrer Sierra, S. (2014). Trazado de la Vía Nova Romana entre las mansiones de Bergido e Interamnio Flavio. Nuevas perspectivas. Estudios bercianos, 38, 11-19.
Gautier, A. (1987). Taphonomic groups: how and why? Archaeozoologia, I, 47-52.

Juan Tovar, L. C. (2012). Las cerámicas imitación de sigillata en el occidente de la Península Ibérica durante el siglo V d. C. En D. Bernal Casasola y A. Ribera i Lacomba (Eds.). Cerámicas hispanorromanas II. Producciones regionales (pp. 97-129). Cádiz: Universidad de Cádiz.

Lemonnier, P. (1986). The study of material culture today: toward an anthropology of technical systems. Journal of anthropological archaeology, 5, 147-186. DOI: https://doi. org/10.1016/0278-4165(86)90012-7

López Quiroga, J. (2017): Hábitat, poblamiento y territorio en la Gallaecia de la época sueva. En J. López Quiroga (Ed.). In tempore sueborum. El tiempo de los suevos en la Gallaecia (411-585) (pp.163-171). Ourense: Deputación Provincial de Ourense.

López Quiroga, J. y Rodríguez Lovelle, M. (1999). Castros y castella tutiora de época sueva en Galicia y norte de Portugal: ensayo de inventario y primeras propuestas interpretativas. Hispania Antiqua, XXIII, 355-374.

Méndez Revuelta, C. (1974-1975). Fragmentos de terra sigillata hispánica del Castelo de Valencia do Sil (Ourense). Cuadernos de Estudios Gallegos, 87-89, 297-303.

Morais, R., Morillo Cerdán, Á., Djaoui, D. y Pereira, P. (2015). Novos paradigmas de investigação: ânforas de fundo plano e cerâmicas comuns utilizadas no transporte de produtos. En A. Martínez Salcedo, M. Esteban Delgrado y E. J. Alcorta Irastorza (Eds.). Cerámicas de época romana en el norte de Hispania y en Aquitania. Producción, comercio y consumo entre el Duero y el Garona (pp. 45-58). Madrid: La Ergástula.

Orton, C., Tyers, P. y Vince, A. (1997). La cerámica en Arqueología. Barcelona: Crítica.

Ozcáriz Gil, P. (2010). Grafitos epigráficos sobre cerámica romana en Navarra. Cuadernos de Arqueología, 18, 331-354.

Paz Peralta, J. A. (1991). Cerámica de mesa romana de los siglos III al VI d.C en la provincia de Zaragoza. Zaragoza: Institución Fernando el Católico.

Pérez Losada, F. (2002). Entre a cidade e a aldea. Estudio arqueo-histórico dos "aglomerados secundarios» romanos en Galicia. A Coruña: Museo Arqueolóxico de A Coruña.

Quirós Castillo, J. A. y Tejado Sebastián, J. M. (2012). Los castillos altomedievales en el noroeste de la Península Ibérica. Bilbao: Universidad del País Vasco.

Roca Roumens, M. y Fernández García, M. I. (Eds.). (1999). Terra Sigillata Hispánica. Centros de fabricación y producciones altoimperiales. Jaén - Málaga: Universidad de Jaén - Universidad de Málaga.

Rodríguez Colmenero, A., Ferrer Sierra, S. y García Tato, I. (2009). Priorato de Xagoaza (Valdeorras, Ourense). Bande: Fundación Aquae Querquennae - Via Nova.

Rodríguez González, X. y Xusto Rodríguez, M. (2019). Santomé. Conxunto arqueolóxico natural. Ourense: Xunta de Galicia. 
Sánchez Pardo, J. C. (2010a). Castros y aldeas galaicorromanas: sobre la evolución y transformación del poblamiento indígena en la Galicia romana. Zephyrus, $L X V, 129-148$. Recuperado de: https://revistas.usal.es/index.php/0514-7336/ article/view/7176/8129

Sánchez Pardo, J. C. (2010b). Poblamiento rural tardorromano y altomedieval en Galicia (ss. V-X). Una revisión arqueológica. Archeologia Medievale, XXXVII, 285-306. DOI: https://doi.org/10.1400/183168

Sánchez Pardo, J. C. (2012). Castros, castillos y otras fortificaciones en el paisaje sociopolítico de Galicia (siglos IV-XI). En J. Quirós Castillo y J. M. Tejado Sebastián (Eds.). Los castillos altomedievales en el noroeste de la Península Ibérica (pp. 29-56). Bilbao: Universidad del País Vasco.

Sánchez Pardo, J. C. (2014). Sobre las bases económicas de las aristocracias en la Gallaecia suevo-visigoda (ca. 530650 d. C.). Comercio, minería y articulación fiscal. Anuario de Estudios Medievales, 44(2), 983-1023. DOI: https://doi. org/10.3989/aem.2014.44.2.10

Sánchez Pardo, J. C., Blanco Rotea, R., Costa-García, J. M., Sanjurjo Sánchez, J., Barrientos Rodríguez, V. y Alonso Toucido, F. (2020). Hacia una interpretación de la secuencia de ocupación del yacimiento de A Cidadela (A Coruña). Spal, 29(1), 1-32. https://doi.org/10.12795/spal.2020.i29.06

Sastre, J. C. y Catalán, R. (2012). Un asentamiento fortificado en la tardoantigüedad: el castro de El Castillón (Santa Eulalia de Tábara, Zamora). En J. Quirós Castillo y J. M. Tejado Sebastián (Eds.). Los castillos altomedievales en el noroeste de la Península Ibérica (pp. 193-211). Bilbao: Universidad del País Vasco.

Soto Arias, P., Fernández Rodríguez, C. y Menéndez Llorente, A. (1998). Cronología y funcionalidad del núcleo habitacional secundario de A Pobra de Valdeorras (Ourense). En A. Rodríguez Colmenero (Ed.). Los orígenes de la ciudad en el noroeste hispánico. Actas del Congreso Internacional (Lugo 15-18 de mayo de 1996) (pp. 1153-1170). Lugo: Grafic-Lugo.

Suárez Otero, J., Gimeno García-Lomas, R. y Fariña Busto, F. (1989). La cerámica medieval en Galicia. En J. A. Gutiérrez González y R. Bohigas Roldán (Eds.). La cerámica medieval en el norte y noroeste de la Península Ibérica (pp. 285-301). León: Universidad de León.

Tejerizo García, C. (2016). Construyendo la casa por los cimientos: consideraciones acerca de la cerámica de la primera Alta Edad Media en la parte central de la cuenca del Duero. En J. A. Quirós Castillo y A. Vigil-Escalera (Eds.). La cerámica de la Alta Edad Media en el cuadrante noroeste de la Península Ibérica (siglos V-X) (pp. 229-254). Bilbao: Universidad del País Vasco.

Tejerizo García, C. (2020). El poblamiento en el interior de la Gallaecia entre el final del Imperio Romano y la Alta Edad Media: nuevos datos, nuevas propuestas. Studia histórica. Historia Medieval, 38(2), 155-187. POI: https://doi. org/10.14201/shhme2020382155187

Tejerizo García, C. y Canosa Betés, J. (2018). Power, control and social agency in post-roman northern Iberia: an archaeological analysis of hillfort occupations. Journal of Medieval Iberian Studies, 10(3), 295-323. DOI: https://doi. org/10.1080/17546559.2018.1504383

Tejerizo García, C., Rodríguez González, C. y Fernández Pereiro, M. (2018). Materiais cerámicos tardíos (ss. IV-VI d. C.) no castro de Viladonga. CROA. Boletín da Asociación de Amigos do Museo do Castro de Viladonga, 28, 36-52.

Tejerizo García, C., Rodríguez González, C. y Fernández Pereiro, M. (2019). ¿Continuidad o discontinuidad en los castros del noroeste? Una revisión del yacimiento de Viladonga (Castro de Rei, Lugo). Spal, 28(2), 279-313. DOI: https://doi. org/10.12795/spal.2019.i28.22

Tejerizo García, C., Scaro, A. y Daflon, E. C. (2019). Materiales inéditos del asentamiento fortificado de Valencia do Sil (Vilamartín de Valdeorras, Ourense). Gallaecia, 38, 71-101. DOI: https://doi.org/10.15304/gall.38.5949

Tejerizo García, C. y Vigil-Escalera Guirado, A. (2017). Castro Ventosa y La Cabeza de Navasangil: una revisión de sus secuencias de ocupación y del fenómeno de los asentamientos fortificados altomedievales. Nailos, 4, 129-161.

Varela Barrios, C., Cavada Nieto, M. M. y Rodríguez González, X. (1997). La circulación monetaria en el conjunto arqueológico de Santomé (Ourense), siglos I al V d. C. Boletín Auriense, 27, 51-106.

Vegas, M. (1973). Cerámica común romana del Mediterráneo occidental. Barcelona: Universidad de Barcelona.

Veiga Romero, A. M. (2009). Los mosaicos de A Cigarrosa. Historia de un hallazgo. Pieza del mes, Noviembre 2009. Ourense: Museo arqueolóxico provincial de Ourense.

Vigil-Escalera, A. (2003). Cerámicas tardorromanas y altomedievales de Madrid. En L. Caballero Zoreda, P. Mateos y M. Retuerce (Eds.). Cerámicas tardorromanas y altomedievales en la Península Ibérica (pp. 371-387): Anejos de Archivo Español de Arqueología, XXVIII. Madrid: Consejo Superior de Investigaciones Científicas.

Vigil-Escalera, A. (2006). La cerámica del período visigodo en Madrid. Zona arqueológica, 8, 705-716.

Vigil-Escalera, A. (2013). Las últimas producciones de TSHT en el interior peninsular. Ex officina hispania. Cuadernos de la SECAH, 1, 11-24.

Vigil-Escalera, A. (2015). Los primeros paisajes altomedievales en el interior de Hispania. Registros campesinos del siglo quinto d. C. Bilbao: Universidad del País Vasco.

Vigil-Escalera, A. (2018). Los últimos 30 años de la arqueología de época visigoda y altomedieval. En J. A. Quirós Castillo (Ed.). Treinta años de Arqueología Medieval en España (pp. 271-294). Oxford: Archaeopress.

Vigil-Escalera, A. y Tejerizo García, C. (2014). Asentamientos fortificados altomedievales en la Meseta: algunas distorsiones historiográficas. En R. Catalán Ramos, P. Fuentes Melgar y J. C. Sastre Blanco (Eds.). Las fortificaciones en la tardoantigüedad. Élites y articulación del territorio (siglos V-VIII d. C.) (pp. 229-245). Madrid: La Ergástula. 